Full length article

\title{
Screening of perfused combinatorial 3D microenvironments for cell culture
}

\author{
Diana Lopes $^{\text {a }}$, C. Fernandes ${ }^{\text {b }}$, J. Miguel Nóbrega ${ }^{\text {b }}$, Sónia G. Patrício a ${ }^{\text {, Mariana B. Oliveira }}{ }^{\text {a,*, }}$ \\ João F. Mano ${ }^{a, *}$ \\ ${ }^{a}$ Department of Chemistry, CICECO - Aveiro Institute of Materials, Campus Universitário de Santiago, 3810-193 Aveiro, Portugal \\ b Institute for Polymers and Composites/i3N, University of Minho, Campus de Azurém, 4800-058 Guimarães, Portugal
}

\section{A R T I C L E I N F O}

\section{Article history:}

Received 7 January 2019

Received in revised form 23 June 2019

Accepted 25 June 2019

Available online 27 June 2019

\section{Keywords:}

Flow perfusion

High-throughput screening

3D microenvironments

Stem cell differentiation

Cell-matrix interactions

\begin{abstract}
A B S T R A C T
Biomaterials combining biochemical and biophysical cues to establish close-to-extracellular matrix (ECM) models have been explored for cell expansion and differentiation purposes. Multivariate arrays are used as material-saving and rapid-to-analyze platforms, which enable selecting hit-spotted formulations targeting specific cellular responses. However, these systems often lack the ability to emulate dynamic mechanical aspects that occur in specific biological milieus and affect physiological phenomena including stem cells differentiation, tumor progression, or matrix modulation. We report a tailor-made strategy to address the combined effect of flow and biochemical composition of three-dimensional (3D) biomaterials on cellular response. We suggest a simple-to-implement device comprising (i) a perforated platform accommodating miniaturized 3D biomaterials and (ii) a bioreactor that enables the incorporation of the biomaterial-containing array into a disposable perfusion chamber. The system was upscaled to parallelizable setups, increasing the number of analyzed platforms per independent experiment. As a proof-of-concept, porous chitosan scaffolds with $1 \mathrm{~mm}$ diameter were functionalized with combinations of $5 \mathrm{ECM}$ and cell-cell contact-mediating proteins, relevant for bone and dental regeneration, corresponding to 32 protein combinatorial formulations. Mesenchymal stem cells adhesion and production of an early osteogenic marker were assessed on-chip on static and under-flow dynamic perfusion conditions. Different hit-spotted biomaterial formulations were detected for the different flow regimes using direct image analysis. Cell-binding proteins still poorly explored as biomaterials components amelogenin and E-cadherin - were here shown as relevant cell response modulators. Their combination with ECM cell-binding proteins - fibronectin, vitronectin, and type 1 collagen - rendered specific biomaterial combinations with high cell adhesion and ALP production under flow. The developed versatile system may be targeted at widespread tissue regeneration applications, and as a disease model/drug screening platform.
\end{abstract}

\section{Statement of Significance}

A perfusion system that enables cell culture in arrays of three-dimensional biomaterials under dynamic flow is reported. The effect of 31 cell-binding protein combinations in the adhesion and alkaline phosphatase (ALP) production of mesenchymal stem cells was assessed using a single bioreactor chamber. Flow perfusion was not only assessed as a classical enhancer/accelerator of cell growth and early osteogenic differentiation. We hypothesized that flow may affect cell-protein interactions, and that key components driving cell response may differ under static or dynamic regimes. Indeed, hit-spotted formulations that elicited highest cell attachment and ALP production on static cell culture differed from the ones detected for dynamic flow assays. The impacting role of poorly studied proteins as E-cadherin and amelogenin as biomaterial components was highlighted.

(c) 2019 Acta Materialia Inc. Published by Elsevier Ltd. All rights reserved.

\footnotetext{
* Corresponding authors.

E-mail addresses: mboliveira@ua.pt (M.B. Oliveira),jmano@ua.pt (J.F. Mano).
} 


\section{Introduction}

The poor isolation of the role of individual factors and their interplay on human tissues healing ability hinders the development of simplified, yet relevant and effective, implantable tissue engineering systems and in vitro testing devices [1]. Deconstructed biophysical and structural elements can be used as a powerful source to drive the bio-instructed potential of biomaterials [2]. To do so, the rational testing of compositional variates and their synergic role with other native niche aspects (such as mechanical stimuli) is necessary to successfully establish a solid bridge between fundamental biology and the effective design of engineered systems [3].

The extracellular matrix (ECM) is accepted as a cornerstone aspect for the maintenance of tissues function and regeneration capability. Since it is the three-dimensional (3D) matter that embeds cells, it provides mechanical cues and physical/structural support to tissues, is composed of molecules secreted by the tissues' own cells, and regulates several signaling pathways [4]. Such phenomena involve cell-cell and cell-matrix adhesion mediation proteins, which also have significant roles in the recruitment and binding of growth factors that trigger signaling cascades commonly involved in cell differentiation signaling [5]. Different proteins that compose the ECM are known to dictate specific cell responses on their own. However, in physiological situations, ECM proteins act as part of a coordinated system that comprises other proteins and molecules [6]. Besides the challenging task of understanding the biochemical diversity of the ECM, the use of 3D systems capable of resembling the native ECM architecture and micromechanical environment is also of utmost importance to achieve in vitro/in vivo correlating results [7-9] and to identify critical aspects to increase the yield of in vitro approaches [10-13].

Mechanical factors have proven to be powerful adjuvants of regeneration [14]. These stimuli naturally occur in human tissues, and their application has been relevant for the development of cellular in vitro-modulating strategies [15]. Bioreactors are a useful tool due to their ability to maintain 3D ECM-mimetic constructs under conditioning stress [16]. Perfusion bioreactors were reported to enhance the homogeneous distribution of cells inside scaffolds and to provide increasing fluid circulation inside biomaterials' structure, enhancing the accessibility of oxygen and vital nutrients to cells $[17,18]$. Operating conditions include the administration of continuous or pulsatile flow to pose significant shear stress on cells $[19,20]$, or the promotion of effective medium perfusion with neglectable mechanical stimulation [21]. Bancroft et al. [22] described a seminal approach based on the use of a perfusion bioreactor for the stimulation of stem cells seeded on 3D polymeric scaffolds targeting bone regeneration. Healthy bone is known to remodel as a response to mechanical stress [23], and studies focusing on the role of perfusion on primary bone cells and stem cells showed increased mineralized matrix deposition in a shear flow dose-dependent manner [24-26].

High-throughput screening has enabled the characterization of multivariate systems in a cost- and time-saving manner [27-32]. While several high-throughput screening platforms have been applied to assess the osteogenic potential of biomaterials [31,3337], those and other in vitro and in vivo high-throughput screening experiments have mostly been performed using platforms limited to static setups $[38,39]$. Flow perfusion studies targeting tissue engineering have mostly been limited to experiments using a low number of biomaterials. Therefore, the modulatory effect of dynamic flow on the response of cells cultured on chemically diverse biomaterials is still poorly explored. Moreover, the effect of dynamic perfusion on stem cells has often been addressed as an "enhancing" and/or accelerating factor for cell proliferation and differentiation. We hypothesize that screening arrays of combinatorial biomaterials (tailored to present different cell-binding domains) in the presence/absence of flow may enlighten the role of mechanical stimulation as a modulating agent of cellbiomaterials interactions.

Here, we report the screening of the effect of a library of 3D biomaterials on BMSCs response in the presence or absence of a flow perfusion flow. For that, a simple and affordable bioreactor was designed. Miniaturized chitosan scaffolds were patterned on a flexible perforated hollow platform, and each individual scaffold was chemically modified with a 5-factor combinatorial protein system, comprising proteins associated with ameliorated cell adhesion, proliferation and osteogenic differentiation. Three native bone cell-binding ECM proteins with distinct roles - type 1 collagen (C), fibronectin (F), and vitronectin (V) - were selected. Type 1 collagen is the most common protein both in adult and developing bone [6]. Fibronectin is also a native component of bone, and its cell-binding RGD is one of the most widely studied cell-binding domains $[40,41]$. Although these two bone ECM proteins have induced successful MSCs osteogenic differentiation, their action is mostly regulated by tailored biophysical parameters such as stiffness [42]. Vitronectin has been much less explored in the realm of biomaterials. Its role in bone has been classically correlated with osteoclasts' function, and more recently with osteoblasts function [43]. Previously, its combination with collagen has been associated with the osteogenic differentiation [44]. Despite not being natively present in bone, amelogenin (A) was capable of inducing MSCs osteogenic differentiation in biomaterial-free in vitro experiments [45]. However, its incorporation in biomaterials targeting bone regeneration has not been directly explored. Finally, E-cadherin (E) was selected for its reported role on improved cellular proliferation of MSCs [46], and we hypothesized that its addition to the system could be effective on promoting the simultaneous BMSCs proliferation during osteogenic differentiation. BMSCs response under (i) static conditions and (ii) continuous flow perfusion conditions was assessed concerning cell adhesion and production of the osteogenic early marker alkaline phosphatase (ALP). The technology reported here allowed disclosing combined effects of dynamic perfusion and multivariate biomaterial compositions on stem cells response.

\section{Materials and methods}

\subsection{Preparation of hollow arrayed platform}

A solution of polydimethylsiloxane (PDMS, Elastomer Kit, Dow Corning) in a ratio of 5:1 (PDMS:curing agent) was prepared and degassed under vacuum for $1 \mathrm{~h}$. A volume of $3 \mathrm{~mL}$ was pipetted onto a mold, schematically represented on Fig. 1A, B. The molds comprised a perforated Teflon ${ }^{\circledR}$ base and hollows covered with stainless steel spikes (purchased in a local commerce) with $1 \mathrm{~mm}$ circular diameter. The molds containing PDMS solution were again degassed under vacuum for $1 \mathrm{~h}$ and cured in an oven (Oven/Laboratory dryer, Ecocell 55 Frilabo) at $70^{\circ} \mathrm{C}$ for $1 \mathrm{~h}$. The solid PDMS perforated platform was removed from the mold and showed approximately $2 \mathrm{~mm}$ height and $4 \times 4 \mathrm{~cm}^{2}$ area. The hollows had $1 \mathrm{~mm}$ circular diameter.

\subsection{Preparation of microarrayed miniaturized 3D chitosan scaffolds}

A $0.9 \%$ chitosan (medium molecular weight, deacetylation degree $\sim 75 \%$, Sigma-Aldrich) solution was prepared using glacial acetic acid (LabChem) at $1 \%(\mathrm{w} / \mathrm{v})$. A volume of $3 \mu \mathrm{L}$ was pipetted 


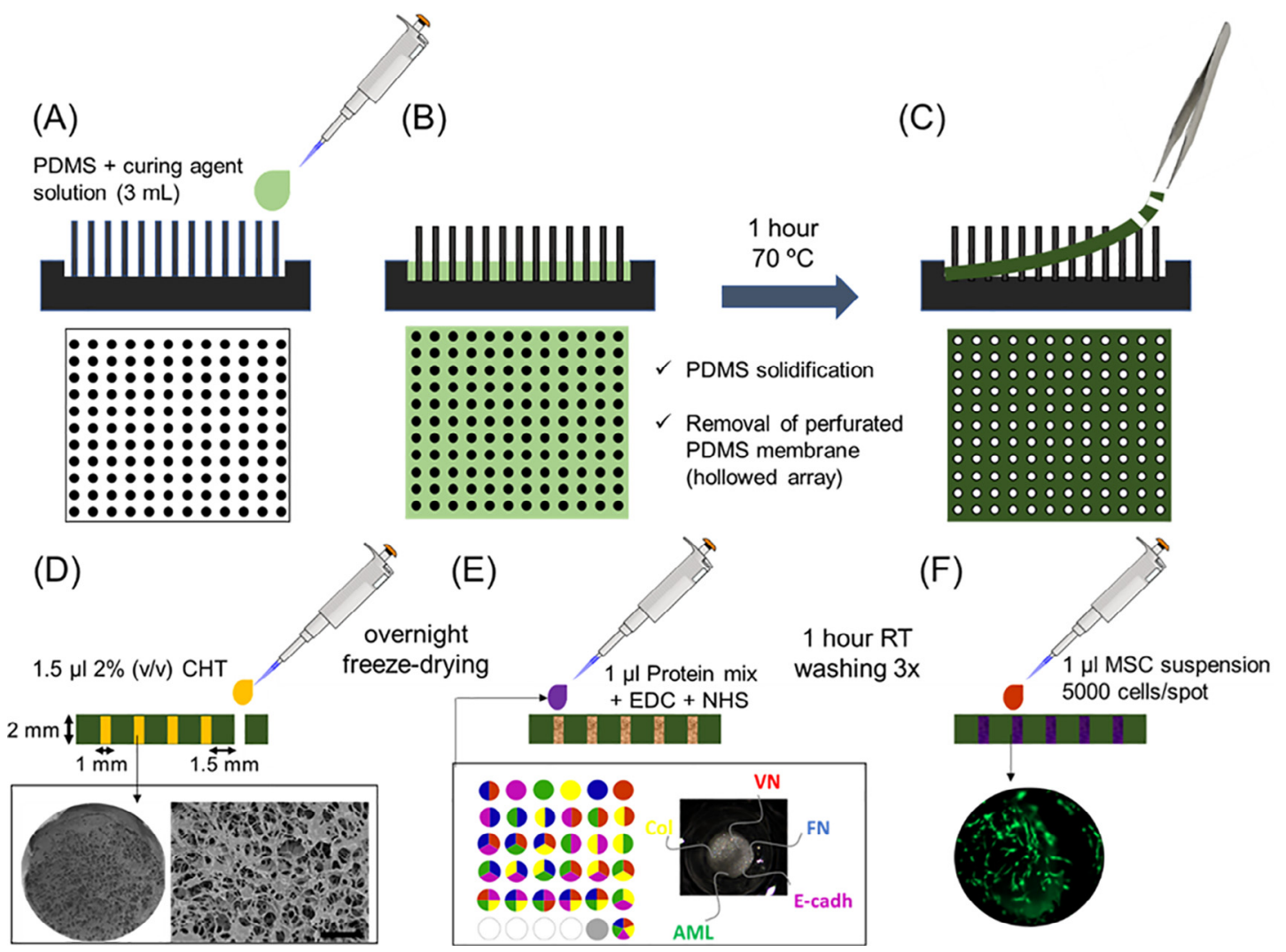

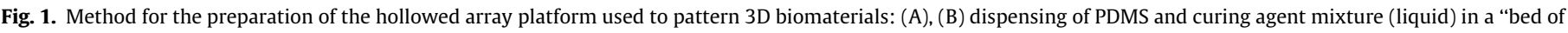

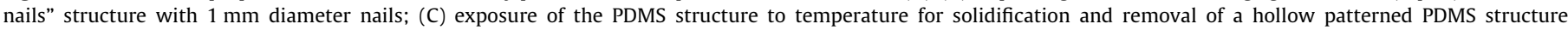

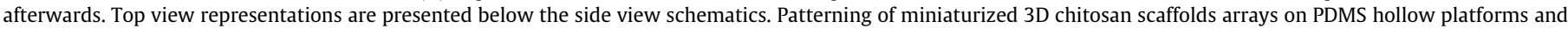

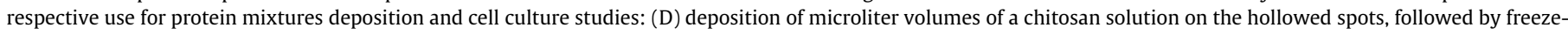

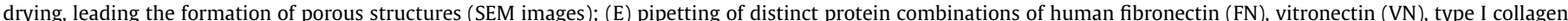

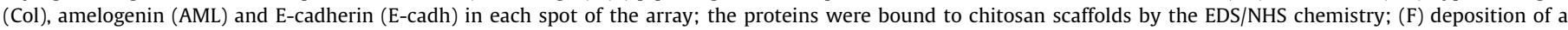
suspension of BMSCs on each protein-modified and control chitosan scaffolds for further microscopic assessment of cell response.

onto individual wells of the PDMS platform. To avoid any loss of solution, the platforms were suspended using two micropipette tips in each side during the pipetting step. The platform containing chitosan solution in the wells was frozen at $-20^{\circ} \mathrm{C}$ for $4 \mathrm{~h}$, and then freeze-dried (LyoQuest Plus Eco,VWR) overnight. The scaffolds were then neutralized by adding droplets of $1 \mathrm{M}$ sodium hydroxide $(\mathrm{NaOH}$, Eka, AkzoNobel) solution prepared in $70 \%(\mathrm{v} / \mathrm{v})$ ethanol (Valente \& Ribeiro). After 10 min neutralization, the whole platforms were washed with distilled water for $30 \mathrm{~min}$ (three cycles of $10 \mathrm{~min}$ ). The samples were frozen again at $-20^{\circ} \mathrm{C}$ for $4 \mathrm{~h}$ and freeze-dried overnight. The platforms were sterilized prior to cell culture by exposure to UV irradiation for $30 \mathrm{~min}$ in each side of the platform (Laminar Flow Cabinet S@femate Eco $1.2 \mathrm{~m}$, EuroClone $^{\circledR}$ ).

\subsection{Preparation of protein solutions}

Five human proteins were used in this study: fibronectin (F, Sigma Aldrich), vitronectin (V, Sigma Aldrich), E-cadherin (E, Advanced BioMatrix), collagen type I (C, Sigma Aldrich) and amelogenin (A, AMELX, ab139212, Abcam). Solutions of the 5 proteins were prepared by dissolution of the stock solution in a phosphate buffered saline solution (PBS, ThermoScientific). The protein solutions were all diluted to the same final concentration, $0.05 \mathrm{mg} / \mathrm{mL}$, in a total protein amount in a range used by others for protein surface immobilization and bone tissue regeneration studies $[37,47]$. Protein solutions used for immobilization on chitosan scaffolds were prepared with equal proportions of each protein. The final protein solutions had the same final mass of each individual protein.

\subsection{Protein immobilization onto miniaturized chitosan 3D scaffolds}

Solutions of $\mathrm{N}$-hydroxysuccinimide (NHS, Sigma Aldrich) and $N$-(3-Dimethylaminopropyl)- $N$ '-ethylcarbodiimide hydrochloride (EDC, Fluka) were added to the protein solutions, in a proportion of $1: 1: 2,(v / v)$ EDC:NHS:protein solution, accordingly to a previously reported method [47]. EDC and NHS concentrations in the protein solutions were $2 \mathrm{mM}$ and $5 \mathrm{mM}$, respectively. A volume of $1 \mu \mathrm{L}$ of each protein mixture was pipetted onto single scaffolds and reacted for one hour at room temperature. Single platforms were then washed in $100 \mathrm{~mL}$ of sterile PBS (changed three times).

\subsection{Morphological analysis of miniaturized 3D scaffolds arrays: scanning electron microscopy}

An analytical field emission scanning electron microscope (SEM) SU-70 (Hitachi, Japan), operated at $15 \mathrm{kV}$, was used to study the morphology of the patterned scaffolds. All samples were fixed by mutual conductive adhesive tape. Before analysis, all samples were coated with a thin layer of gold/palladium using a sputter coater. 


\subsection{Cell expansion}

Bone marrow-derived mesenchymal stem cells (BMSCs) were purchased from LGC Standards, ATCC. The undifferentiated cells were cultured and expanded under basal condition, using Minimum Essential Alpha Medium (alpha-MEM, Sigma, USA), supplemented with $10 \%(\mathrm{v} / \mathrm{v})$ fetal bovine serum (ThermoFisher Scientific) and $1 \%(\mathrm{v} / \mathrm{v})$ penicillin-streptomycin (ThermoFisher Scientific).

\subsection{Cell seeding}

A suspension of $5000 \mathrm{BMSC}$ cells/ $\mu \mathrm{L}$ was pipetted at a volume of $1 \mu \mathrm{L}$ onto the scaffolds with previously immobilized proteins. Cells were left to attach to the material for $30 \mathrm{~min}$ at $37^{\circ} \mathrm{C}$. After this seeding step, the platforms were washed once with PBS and incubated $\left(\mathrm{CO}_{2}\right.$ Incubator, Model $\mathrm{C} 170$, Binder $)$ at $37{ }^{\circ} \mathrm{C}, 5 \% \mathrm{CO}_{2}$ with $5 \mathrm{~mL}$ of cell culture medium using non-adherent cell culture plates. Cells were used on passages of P2 to P6, and cell culture medium was exchanged every 2 days.

\subsection{Bioreactor assembly}

A perfusion bioreactor was assembled to withstand two parallel replicates of each individual setup. The number of parallel replicates depends solely on the available channels of the peristaltic pump used to perfuse the medium. Each individual set of the bioreactor comprised: (i) one chamber with cell culture medium, capable of holding the hollow PDMS platform containing 3D scaffolds arrays and respective adhered cells, (ii) tubes (Tygon ST R3607, Ismatec, $3.17 \mathrm{~mm}$ outer diameter) for medium transportation, (iii) one individual reservoir of cell culture medium (Schott, $250 \mathrm{~mL}$ ), and (iv) one peristaltic pump (REGLO digital MS-2/6160). The tubes were connected to the cell culture medium reservoir through a commercially available screw cap (Screw cap HPLC, GL 45, 4 ports, Duran ${ }^{\circledR}$ ) with four ports (3.0 mm diameter). The inlet tube, that drove medium flux to the bioreactor chamber, was inserted inside the cell culture medium; the outlet tube, which recirculated the cell culture medium back to the reservoir, was left about $1 \mathrm{~cm}$ above the cell culture medium meniscus. The tubes connecting the medium reservoir and the bioreactor chamber were coupled in the channels of a peristaltic pump. Gas exchange in the cell culture medium was promoted through the assembly of two $0.2 \mu \mathrm{m}$ sterile cellulose acetate syringe filters $(30 \mathrm{~mm}$ diameter; Whatmann ${ }^{\mathrm{TM}}$ /GE Healthcare) in the two remaining entries of the reservoir cap. The bioreactor chamber was composed of two sterile $20 \mathrm{~mL}$ polypropylene syringes (VWR) without the respective pistons. Tubes were connected to the outlet of the syringes, and both syringes were attached together containing the perforated arrayed platform in between both syringes. The chamber was sealed using sterile Parafilm ${ }^{\circledR}$ and insulation tape on outer layers. All tube-tube and syringe-tube junctions were also sealed with Parafilm ${ }^{\circledR}$ and insulation tape, which successfully impaired any fluid loss. The schematic representation of the bioreactor assembly is depicted in Fig. 2A, B. A picture of the bioreactor containing two parallel setups (two bioreactor chambers fed by two individual cell culture medium containers) assembled to the same peristaltic pump can be seen in Fig. 2C.

\subsection{Numerical simulations of the bioreactor}

The numerical studies were performed in OpenFOAM computational library and, as described in the main text, comprised two phases: (i) study of a representative region of the 3D scaffold; (ii) study of the flow on the whole bioreactor chamber. On the initial phase, the solver employed in the calculations was simpleFoam, which is appropriate for the calculation of steady state Generalized Newtonian incompressible fluid flows. The geometries and computational meshes required for the numerical studies were generated in Blender and cfMesh, respectively. The relation between the pressure drop and velocity, computed for the representative 3D scaffold region, plotted in Fig. 3B, was fitted to a Darcy porous model using Microsoft Excel. For the calculations done on the global bioreactor, during the second phase of the numerical studies, the solver simplePorousFoam was employed, to allow the definitions of porous regions at the scaffolds, using the Darcy model parameters obtained on the initial phase. To post-process the results a new utility was created in OpenFOAM to calculate the flow in each of the scaffolds, whose IDs are provided in Fig. S3 (Supporting Information). For that purpose, a face set was created at the cross section of each scaffold using the setSet utility, and the new routine
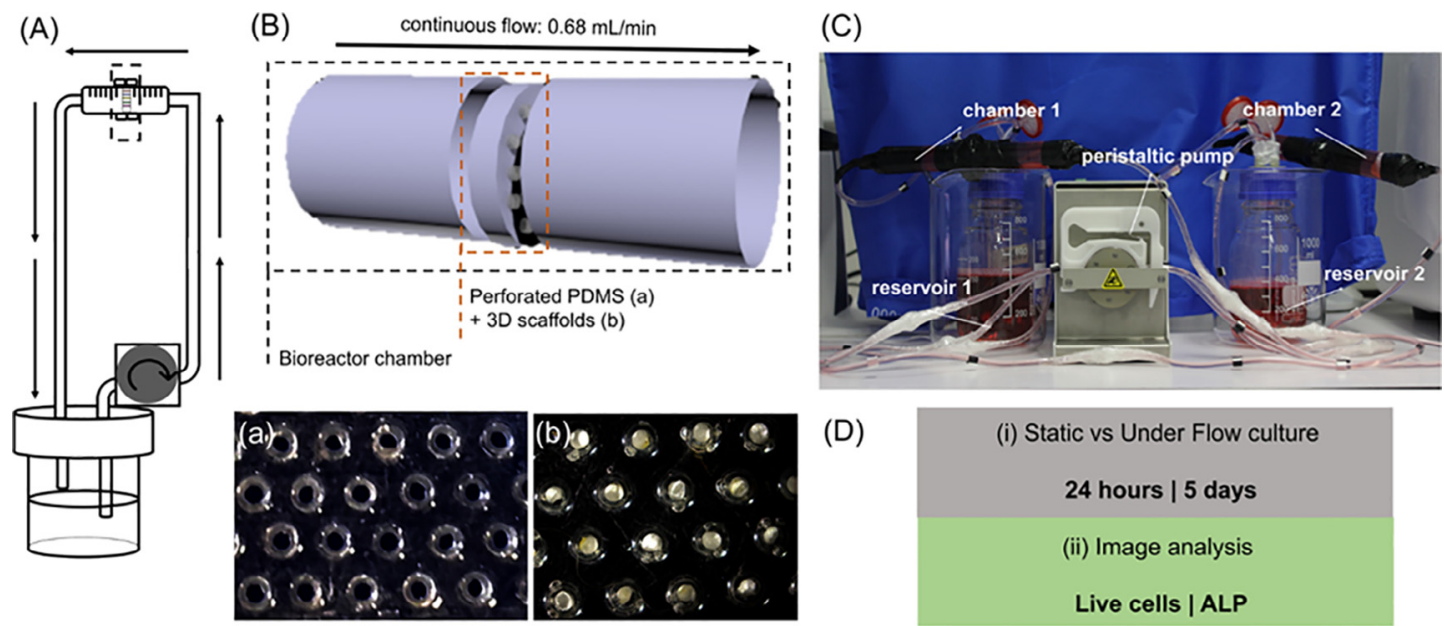



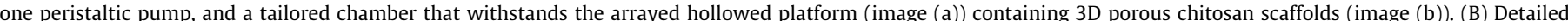

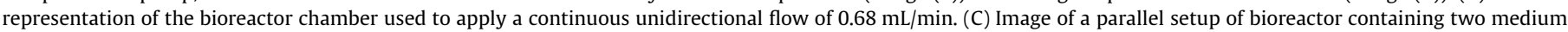

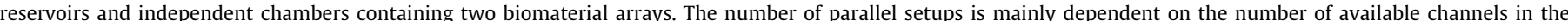

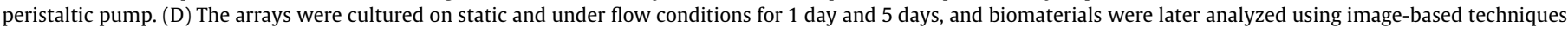
for their content of live cells and alkaline phosphatase (ALP). 
A)

a)

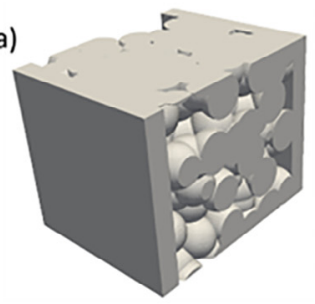

b)

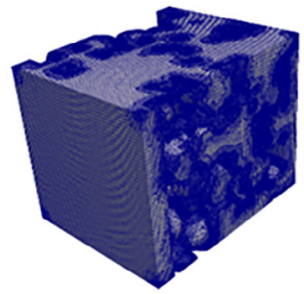

C)

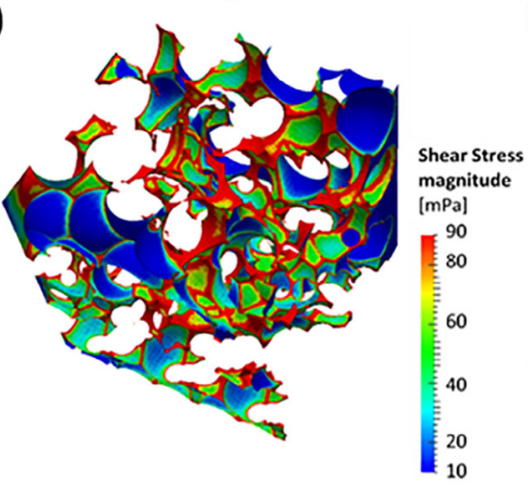

B)

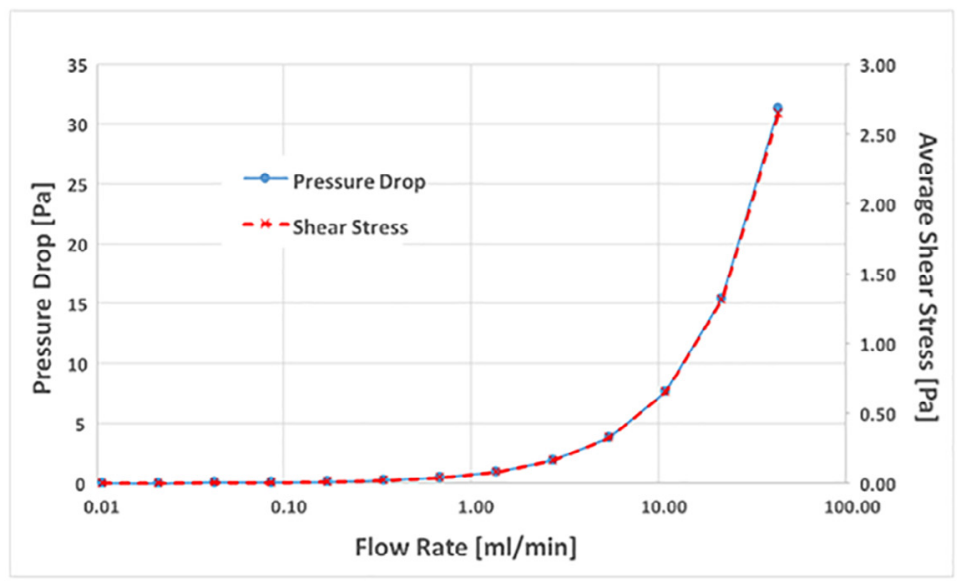

D)

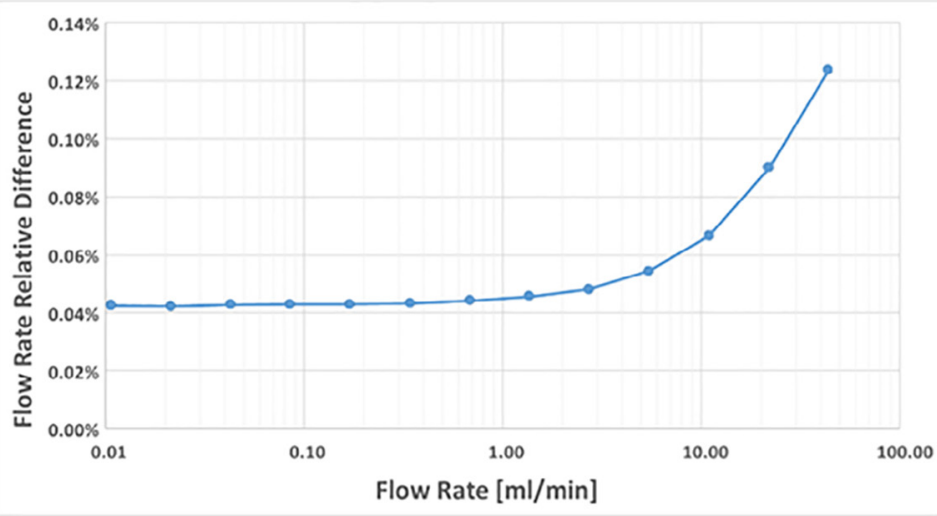

E)

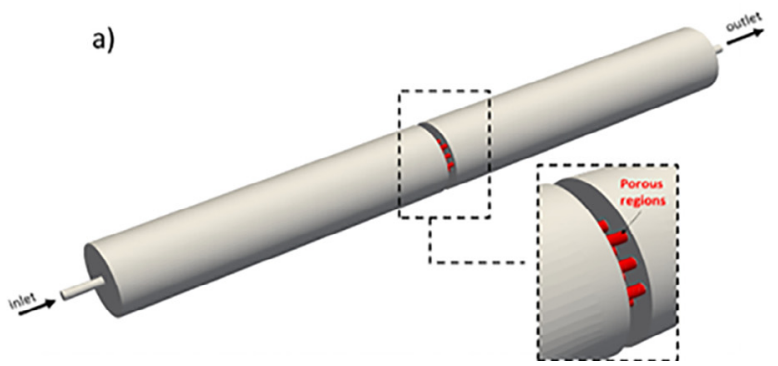

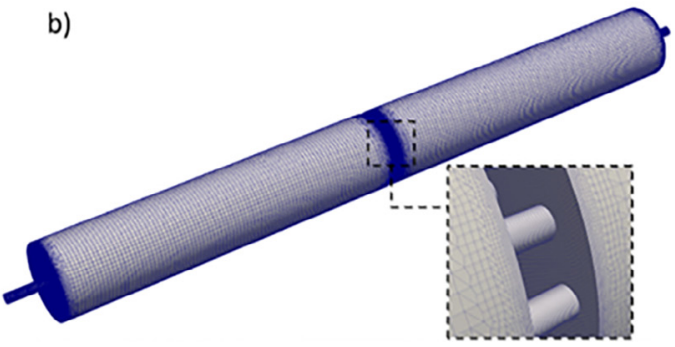

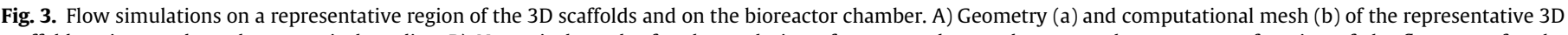

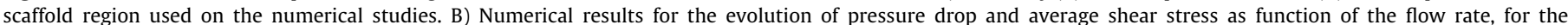



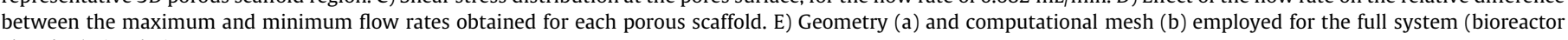
chamber) simulation.

summed the flow on the faces of each face set, to provide the desired individual flow rate in each individual scaffold.

\subsection{Dynamic and static (control) on-chip cell culture}

The PDMS platforms containing an array of scaffolds seeded cells were placed in the bioreactor chamber using sterile tweezers. BMSCs were cultured in the platforms for 1 day, under static conditions, prior to the assembly in the bioreactor. For static control experiments, cell culture continued under static conditions inside suspension Petri dishes, with $8 \mathrm{~mL}$ supplemented cell culture medium. On dynamic culture, after the complete bioreactor sealing, the bioreactor reservoirs and chambers were placed on an incubator at $37{ }^{\circ} \mathrm{C}$ and $5 \% \mathrm{CO}_{2}$. The bioreactor chambers were placed in a horizontal position. The peristaltic pump was set with a flow of
$0.68 \mathrm{~mL} / \mathrm{min}$. The experiments were then carried out for 1 day and 5 days of incubation. To remove the scaffold arrays from the bioreactor, the parafilm ${ }^{\circledR}$ and insulating tape shell used to seal the syringes chamber was cut with a sterile scalpel inside a laminar flow chamber. The platform was then carefully removed using sterile tweezers. All scaffold arrays were washed with sterile PBS, and immediately analyzed for cell viability.

\subsubsection{Viability analysis}

The scaffold arrays retrieved from static and dynamic cell culture were immersed in $2 \mathrm{~mL}$ of sterile PBS containing $4 \mu \mathrm{g}$ of calcein AM (Thermo Fisher Scientific) and $2 \mu \mathrm{g}$ of propidium iodide (PI, Thermo Fisher Scientific) in the incubator at $37^{\circ} \mathrm{C}, 5 \% \mathrm{CO}_{2}$, for $30 \mathrm{~min}$. The platforms were then analyzed using a fluorescence microscope (Axio Imager M2, Zeiss) with both Calcein/propidium 
iodide (PI) filters, at a fixed exposure time of $800 \mathrm{~ms}$. Images were acquired in each individual spot of the platform. Automated data acquisition was performed with a Zeiss M2 microscope (Zeiss) equipped with a controlled xyz table. For image analysis, the area of the scaffolds was selected, and the image was later treated as a "region of interest" (ROI), in which green fluorescence intensity was directly measured using the ZEN software (Zeiss). After the analysis, the chips were fixed with formalin at $4 \%$ (Sigma), at $4{ }^{\circ} \mathrm{C}$, for one day. The semi-quantitative results for calcein AM signal quantification were calculated by dividing the detected intensity in each formulation by the one detected in the protein-free control in each individual time point. Higher ratios represented conditions with higher detected calcein signal.

\subsubsection{ALP quantification analysis}

After fixation with formalin, the platforms were washed twice with distilled water for $30 \mathrm{~min}$, and then immersed in an ALP substrate solution (1-Step ${ }^{\mathrm{TM}}$ NBT/BCIP Substrate Solution, ThermoScientific). The reaction took place at $37^{\circ} \mathrm{C}$, for $4 \mathrm{~h}$. The ALP present in the array was stained in purple. However, a method based on fluorescence analysis was developed to perform rapid and easy analyses of ALP presence in each individual scaffold. Whole platform images were acquired automatically using a fluorescence microscope equipped with a xyz-controlled table, at an exposure time of $60 \mathrm{~ms}$, using the Calcein filter. The chitosan scaffolds show autofluorescence. The places stained for ALP show a nonfluorescent signal, and black spots can be observed in the exact places where ALP is visibly stained. The relative semiquantitative assessment of ALP per scaffold was performed by increasing the fluorescent signal of the all images equally, and by quantifying the fluorescent signal in each individual scaffold. Scaffolds with lower detected fluorescence were the ones with higher amounts of ALP. The semi-quantitative results for ALP quantification were calculated by dividing the detected intensity in each formulation by the one detected in the protein-free control. Lower ratios represented conditions with higher amount of detected ALP.

\subsection{Statistical analysis}

All data was treated and plotted using GraphPad Prism 6 Software. Multivariate factorial ANOVA analysis and calculation of compositional effects was performed using the Design-Expert 10 Software using Response Surface Methodology. A five-component multifactorial approach was designed, in which each protein was labelled in two different levels: existent (level 1) or inexistent (level 0). Statistical significance was considered for factors with $p<0.05$. Hierarchical clustering of data was performed using the PAST 3.19 Software. Box plot charts showing medians, minimum and maximum measured values are depicted in Supporting Information - Figs. S4 and S5.

\section{Results}

\subsection{Design of a miniaturized perforated platform and patterning of miniaturized $3 D$ environments}

Using the device based on hollows filled with biomaterials depicted in Fig. 1A-C, hollows' height, diameter, sectional shape and interunit distance were amenable to be easily tailored to achieve scaffolds with versatile sizes, section shapes and spatial distribution by altering the mold used to cast PDMS. The possible control over PDMS crosslinking extent, through the application of tailored curing temperature, time and proportion of curing agent, may enable the production of platforms with distinct stiffnesses, amenable to be used in complex multi-stimuli experiments. The easy access to miniaturized porous chitosan 3D scaffolds enabled the modification of individual biomaterials with distinct proteincontent formulations (Fig. 1E, F). Here, human proteins including fibronectin, vitronectin and type-I collagen are presented to cells as adhesive proteins present in native human tissues' ECMs, capable of mediating cell-matrix interactions through different membrane integrins [48]. Amelogenin is added to the system as a cellbinding enamel protein strongly associated with the osteogenic commitment of MSCs [45] and improved bone regeneration [49]. E-cadherin is used as a simulator of cell-cell contact, as previously studied on biomaterials' surfaces [50].

\subsection{Design of a perfusion bioreactor compatible with the high- throughput study of protein-BMSCs interactions}

The bioreactor described here was assembled with common, affordable and disposable labware (Fig. 2A-C). The independency from tailor-made pieces facilitates the assembly of this device in any laboratory. The bioreactor chamber was easily closed and isolated using layers of sterile parafilm and insulation tape. Here, the use of micromachined chamber, O-rings and other commonly used accessories was avoided, decreasing costs and handling steps that may culminate in microbial contaminations of the whole setup.

The effect of 31 distinct protein formulations on BMSCs cell adhesion and early osteogenic differentiation on static conditions, or under perfusion flow $(0.68 \mathrm{~mL} / \mathrm{min}$; Fig. 2D) was studied using the high-throughput perfusion bioreactor. Since scaffolds' architecture affects the effective shear stress posed to cells, we performed a computational flow simulation study that enabled predicting the range of shear stress values through the bioreactor, and specifically in the 3D porous regions of the miniaturized scaffolds. The flow simulations were performed to calculate the main flow variables, including the shear stress, at the PDMS platform and throughout the bioreactor chamber. The numerical study was performed using the OpenFOAM computational library [51], and was divided in two phases: (i) analysis of a representative porous scaffold region and (ii) the assessment of the flow on the whole bioreactor chamber, including the perforated PDMS platform containing 3D porous scaffolds, computed in step (i). On the first phase, the flow was modelled in a representative region of the porous scaffolds - represented by a cube with $250 \mu$ m side -, whose geometry was randomly generated, with a porosity of circa $80 \%$ and pore diameter of $60 \mu \mathrm{m}$ (Fig. 3). Both geometry and computational mesh employed at this stage are illustrated in Fig. 3A. The direct numerical simulation of the flow was performed for a range of representative flowrates, up to around $40 \mathrm{~mL} / \mathrm{min}$, to obtain the relation between velocity and pressure drop for the representative porous scaffolds region, as shown in Fig. 3B. The collected data was employed to devise the parameters of the Darcy model characteristic for the scaffolds' porous regions. Results illustrated in Fig. S1 (Supporting Information) show the tortuous nature of the flow while passing though the porous scaffold region.

The effect of the flow rate on the shear stress induced at the pores' surface was also predicted by the numerical code, as illustrated in Fig. 3C, for the flow rate of $0.682 \mathrm{~mL} / \mathrm{min}$, which was applied herein in the characterization of cell-biomaterials interactions. Based on obtained results, the walls of the porous scaffolds were subjected to a shear stresses in the range of $10-90 \mathrm{mPa}$. Based on this result, each individual scaffold of the perforated platform inserted in the bioreactor chamber could be stimulated with shear stresses in the range of the ones reported in previous bioreactor setups comprising 3D biomaterials for cell culture [52-54].

The numerical studies performed on the second phase had the main purpose of verifying the effect of the flow rate on the flow distribution on each individual porous scaffold region. For that, those regions were identified, as shown in Fig. S2 (Supporting 
Information), and the flow rate in each one was calculated for all the numerical runs. Consequently, the numerical analysis consisted on the study of the full bioreactor system using the porous scaffold model obtained in the previous phase, which was employed on the perforated regions. For that, those regions were identified, as shown in Fig. S2 (Supporting Information), and the flow rate in each one was calculated for all the numerical runs performed. Fig. 3D depicts the relative difference of the maximum and minimum flow rates obtained among all the regions, proving that up to $1 \mathrm{~mL} / \mathrm{min}$ flow rates the differences in the flow observed in each individual scaffold are neglectable. A trend to unbalance the flow distribution in different scaffolds of the bioreactor could only be detected above that flowrate. Importantly, even for the highest flow rate considered - $40 \mathrm{~mL} / \mathrm{min}$ - the predicted difference between the maximum and minimum flows is below $0.14 \%$, indicating a still acceptable homogeneity of the flow distribution throughout all scaffolds in the bioreactor. Notice, that the restrictive effect of the porous regions favours the flow distribution uniformity.

Fig. 3E shows both the system geometry and the mesh employed on the numerical runs. Figs. S2 and S3 (Supporting Information) illustrate, respectively, the pressure distribution and respective individual cell region IDs employed to monitor the flow distribution; and the streamlines that were computed for the reference flow rate employed on the experimental studies: $0.68 \mathrm{~mL} / \mathrm{min}$. From the pressure drop distribution (Fig. S2, Supporting Information), it was observed that the scaffold region is responsible for the most pressure drop obtained on the computational domain, a direct outcome of the flow restriction promoted by the porous regions.

\subsection{In vitro characterization of BMSCs response}

The behavior of BMSCs cultured on the 3D scaffold arrays was characterized by image analysis. The calcein signal intensity detected in each individual spot was used as a semi-quantitative indicator of cell number in each biomaterial. ALP is an enzyme which increased activity has been widely reported as an indication of early osteogenic differentiation of MSCs [55]. The loss of autofluorescence from chitosan scaffolds, resulting from the reacted ALP product (without any fluorescence emission), was used as a semi-quantitative method to detect the presence of this protein in single spots. All results were normalized to the protein-free control, and they allowed to infer about the role of additive proteins to the chitosan scaffolds, as well as synergic effects between protein formulations and static/dynamic flow regimes.

The ratio between calcein signal intensity quantified in the protein-free spot (here, "control") and the calcein signal intensity detected on the protein-containing formulations was calculated for all independent platform experiments. Fig. 4 depicts images of on-chip cellular calcein staining on biomaterial formulations that led to highest detection values and low-variability calcein signals after 1 day (panel A) and 5 days (panel B) of cell culture. Normalized mean average values obtained for calcein ratios for all studied conditions are presented in Fig. $5 \mathrm{~A}$, as well as a cluster charts grouping these results (Fig. 5B). The original calculated ratios are presented as box plot charts (presenting median, minimum and maximum measured values) in Fig. S4, Supporting Information.

For 1 day cell culture under static environment, the conditions EC, VECA and FECA showed high and consistent $(p<0.1$; comparison with protein-free control) calcein intensities (Fig. 5A). Other conditions presenting high mean average values for calcein ratios were E, VE, VA, FC, VEC and FCA. One of the most recurrent components of these mixtures is the cell-adhesive protein type-I collagen, which is present in the human native bone ECM. The presence of collagen in the chitosan scaffolds by itself, however, was not enough to trigger a higher cell number in the scaffolds as compared to the protein-free control. Another protein with high predominance in the formulations that elicited higher calcein signal was E-cadherin. Here, the modification of chitosan scaffolds with Ecadherin alone was enough for high calcein signal detection. When allied to cell adhesive ECM proteins - fibronectin, collagen and vitronectin -, E-cadherin showed improved cell adhesion capacity. The mixture of E-cadherin with ECM adhesive proteins was effective on specific binary, ternary and quaternary combinations, indicating that the proteins kept their function even in lower proportion in the formulations. In general, initial BMSCs adhesion to chitosan scaffolds seems to be enhanced in combinatorial protein combinations, instead of single protein formulations. ECM

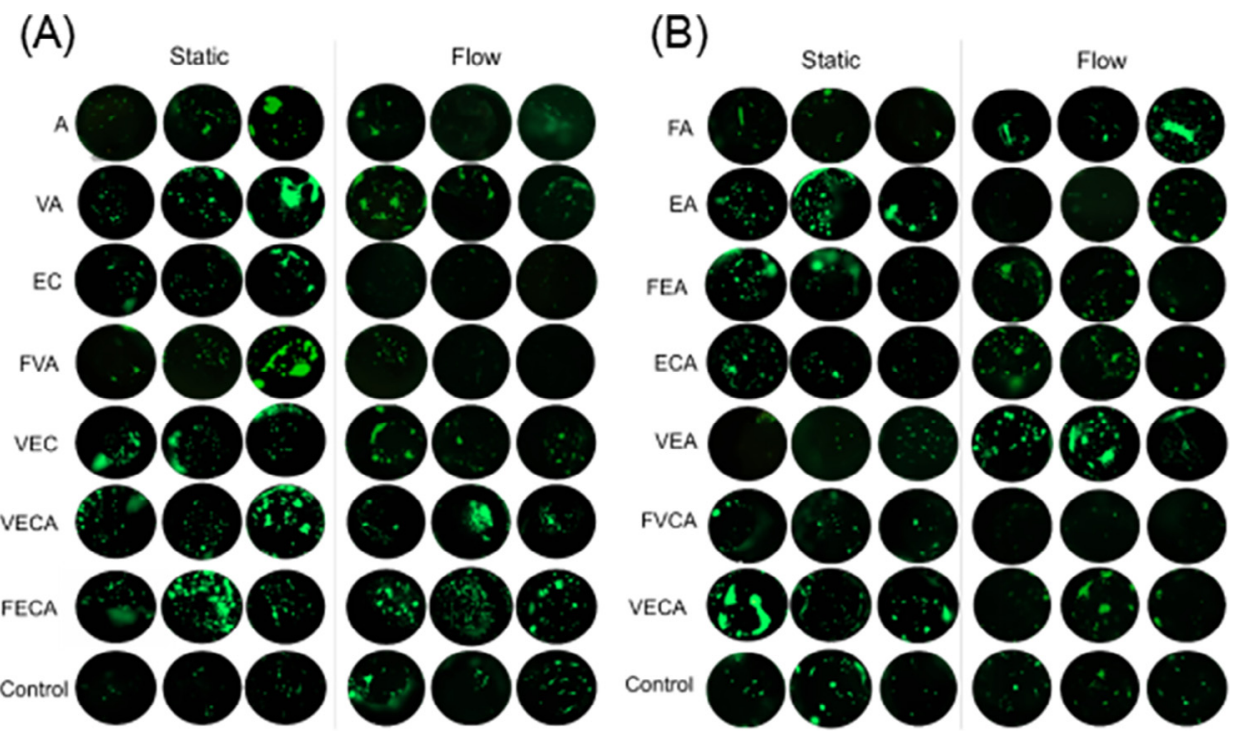




to colour in this figure legend, the reader is referred to the web version of this article.) 


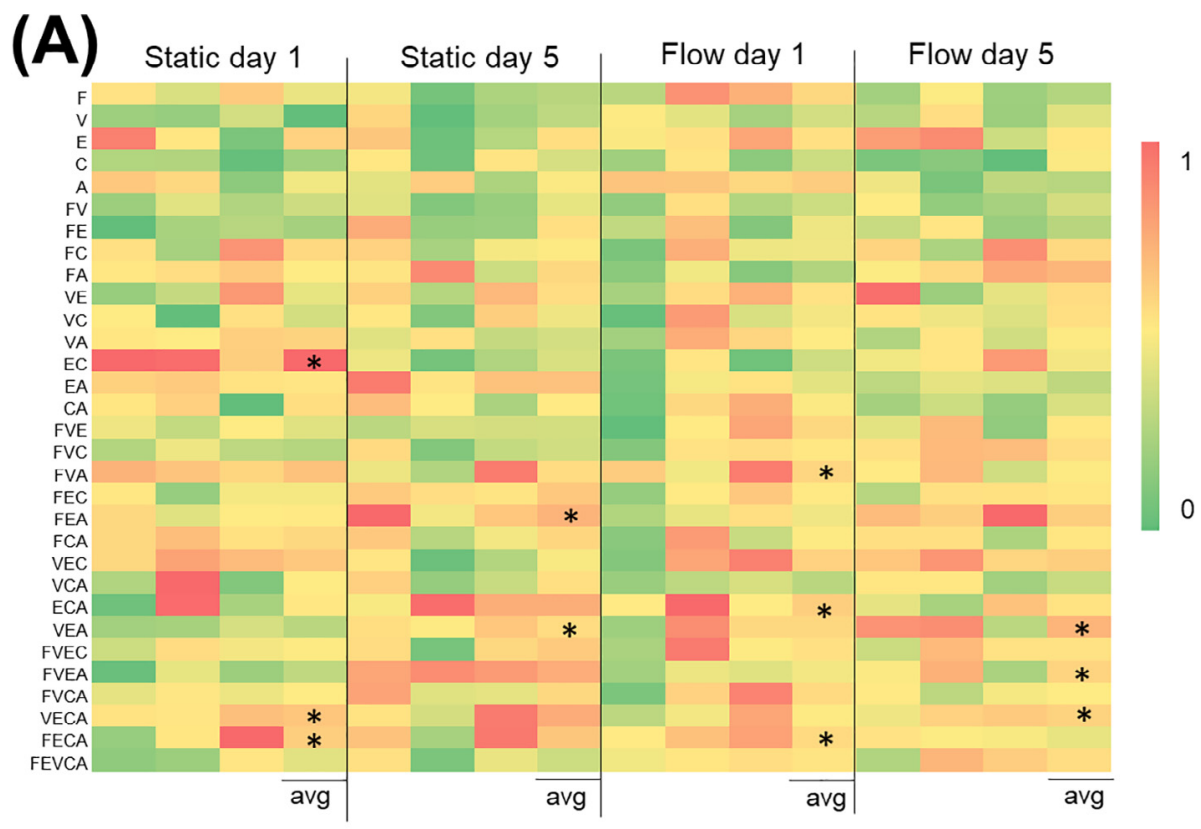

(B)

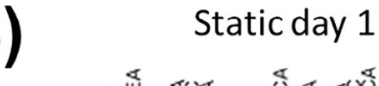

Flow day 1

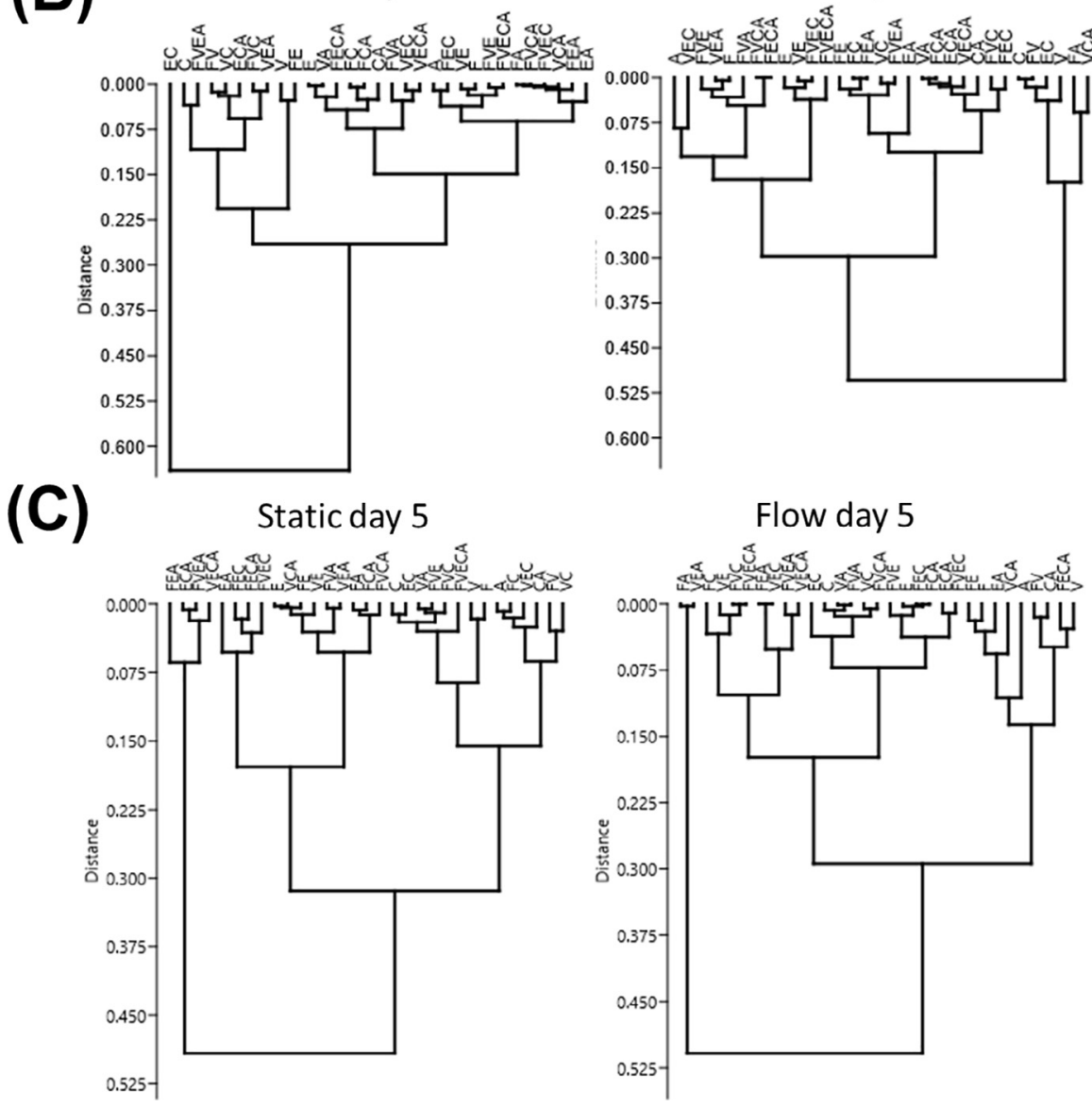

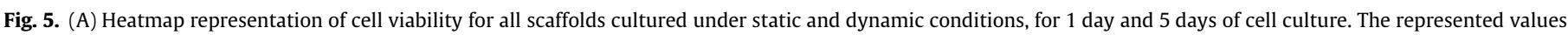



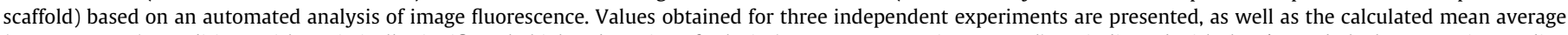

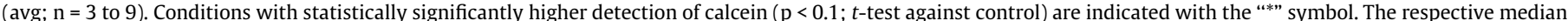

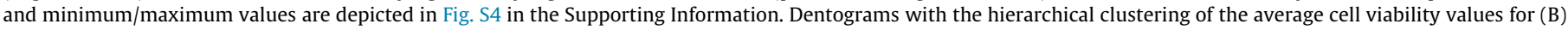
1 day and (C) 5 days of cell culture for static and dynamic conditions. 
adhesive proteins and E-cadherin, also in the presence of amelogenin in certain formulations, seem to have a synergic effect on this phenomenon. After 5 days of static culture, the hit-spotted formulations driving increased and low-variation calcein signal were FEA and VEA. Moreover, EA, VC, FEC, FEA, FVE, ECA, VECA and FVEA also showed the highest mean average ratios. For this time point, combinations of cell-matrix adhesion proteins (here, fibronectin and/or vitronectin), cell-cell contact proteins (here, E-cadherin) and enamel amelogenin promoted the highest number of adherent cells.

For 1 day dynamic culture conditions, highest and least variable calcein signals were detected on FVA, ECA and FECA scaffolds. The interaction between ECM adhesive proteins (fibronectin, type I collagen) along with E-cadherin and amelogenin seem to dictate higher cell adhesion to materials. For 5 days of cell culture under dynamic flow stimulation, VEA, FVEA and VECA presented consistently increased high calcein ratios, corroborating previous results indicating the important role of the interactions between adhesive proteins, E-cadherin and amelogenin as constituents of hit-spotted conditions promoting enhanced cell number on biomaterials.

Despite consistent patterns indicating the combined presence of ECM integrin-binding proteins with E-cadherin and amelogenin as driving forces of effective cell adhesion on biomaterials, the presence of these protein combinations on several 3D biomaterials compositions was not enough to drive higher cell adhesion to the substrates, suggesting that cells respond to specific proteinprotein combinatorial effects, instead of single compositiondriven effects. Indeed, effect analysis using multivariate surface response methods indicated few significant factors as statistically relevant for cell number determination in each biomaterial. These included for 1 day culture (static condition) E-cadherin $(p=0.03)$, type I collagen $(p=0.04)$ and amelogenin $(p=0.02)$ as significant individual factors positively affecting cell number. For 5 days static and dynamic conditions, however, no significant results could be obtained by performing a bulk analysis of the whole data.

Protein-protein interactions have been reported to induce structural and functional changes in different combinations of proteins [56-58]. The interaction of each protein with different cell types also dictates the role of each protein. In a particular example, Heydarkhan-Hagvall et al. [59] reported that scaffolds coated with vitronectin showed higher cell adhesion rates of embryonic stem cells, other than those coated in fibronectin, on a 3D environment. Moreover, although the integrin-mediated interactions between cells and ECM proteins as fibronectin, vitronectin and type I collagen are widely reported [60], the specific cell interaction mechanism of amelogenin is still yet not fully understood. A study made by Kirkham et al. [61], showed that amelogenin interacts with cells through the cell membrane. Lokappa et al. [62] later showed that this interaction was made at the membrane phospholipids, and that the $\mathrm{N}$-terminal of amelogenin may be responsible for this interaction, since enamel malformations of the amelogenin's N-terminal in the disease amelogenesis imperfecta lead to a faulty interaction between cells and the protein [63]. The improving effect of amelogenin on the cell number in the scaffolds, both on static and dynamic culture conditions, may be related to its adhesive interactions with cells through mechanisms that differ from other ECM cell-binding proteins. Another possibility to explain the observed amelogenin's adjuvant effect relies on the possible configurational and structural alterations that amelogenin may induce in other proteins present in the mixtures used to modify the surface of the chitosan scaffolds.

For ALP detection analysis, pictures of the whole platforms were acquired using a fixed exposure time, and a bright signal was detected in the chitosan regions, while on ALP-positive regions a non-emitting signal could be clearly observed (in black, Fig. 6). The calculation of ratios between experimental conditions and the "control" (protein-free) condition in each independent experiment was calculated in the same way as previously described for calcein. The ratio values are presented as box plots (median, maximum and minimum values) on Fig. S5 (Supporting Information), and the normalized average mean values are presented in a heatmap in Fig. 7A, along with the hierarchical clusters (Fig. 7B) of the results for 1 day of cell culture.

After one day of static cell culture, the conditions that led highest and consistent (statistically significant against protein-free control; $p<0.05$ ) ALP quantifications were FE, VC, FVE and FVEC (Fig. 7A). None of the proteins alone led to an increase on ALP quantification. Type-I collagen was highly predominant in mixtures leading high ALP production. E-cadherin was also predominant in the mixtures triggering higher ALP levels. Despite different mesenchymal cadherins are known to mediate bone formation in vivo [64], the role of E-cadherin has not been disclosed
(A)

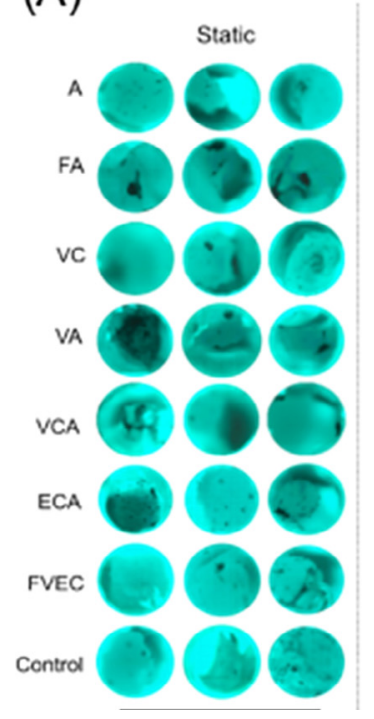

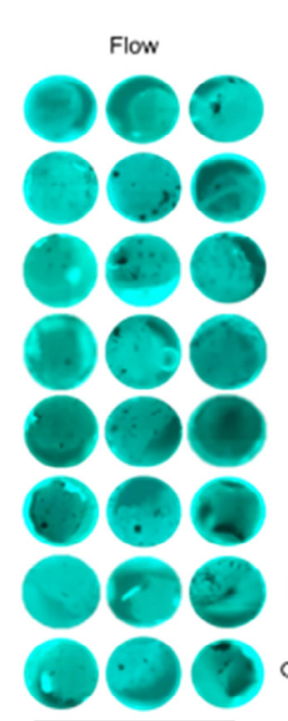

(B)

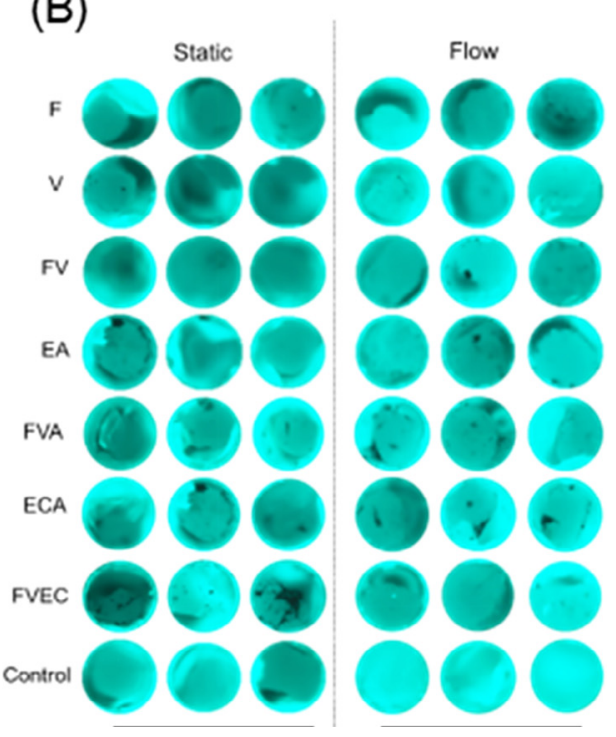

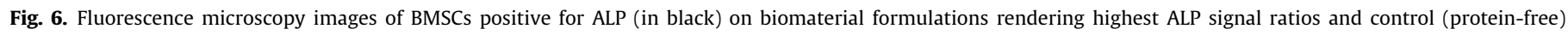
conditions, after (A) 1 day and (B) 5 days of cell culture. Each condition is represented with 3 images from independent experiments. 


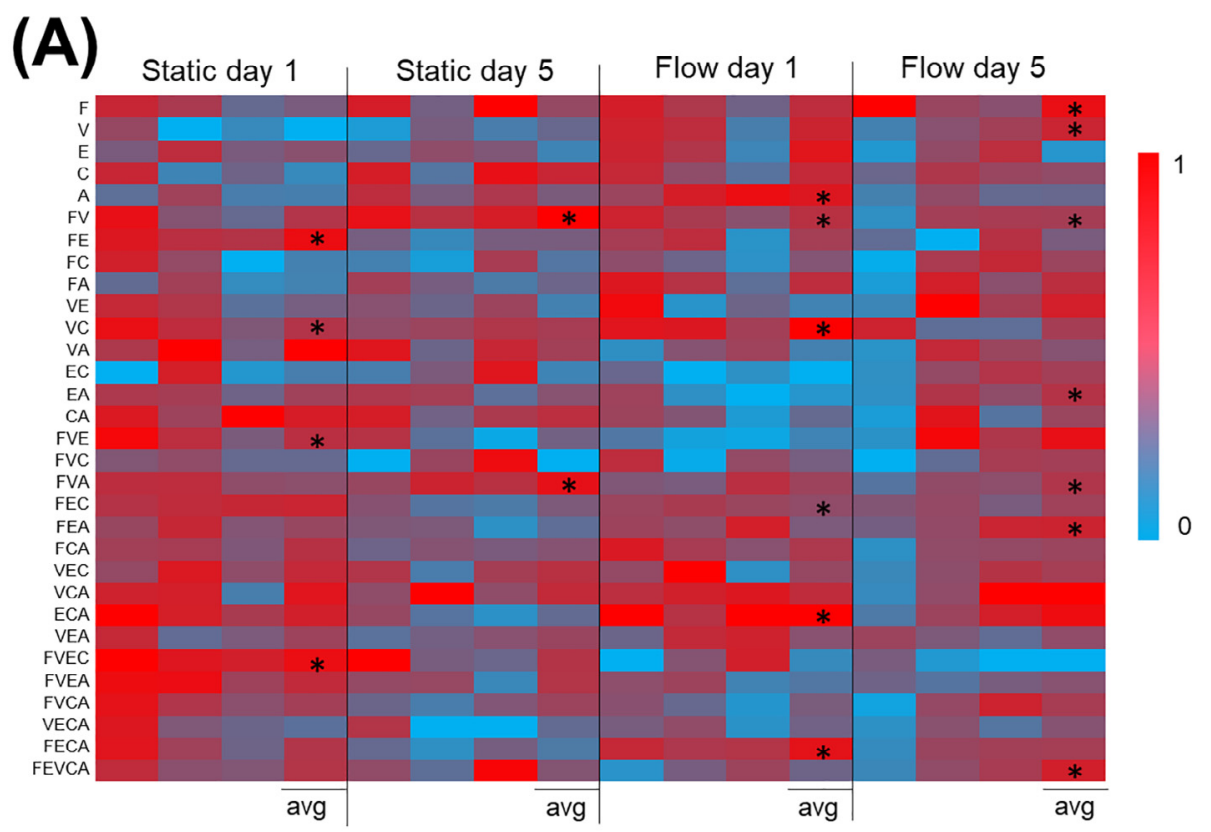

(B)
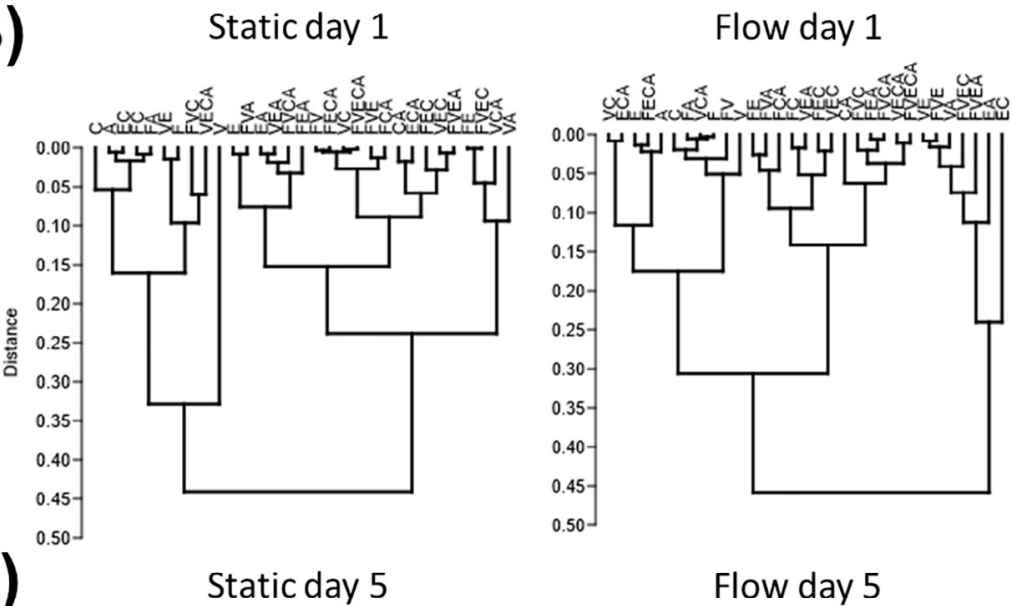

(C)
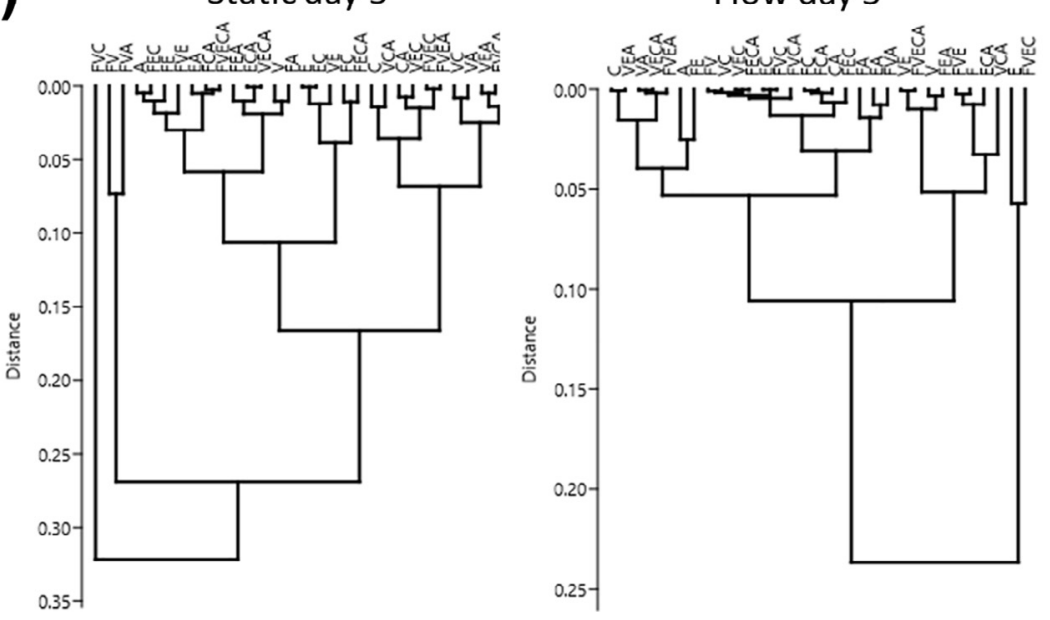

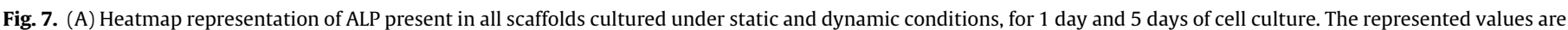

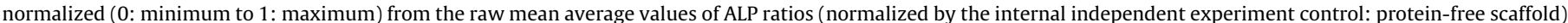

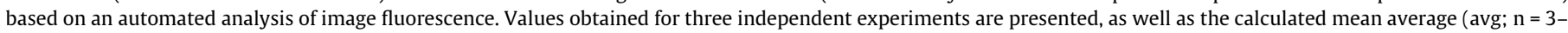

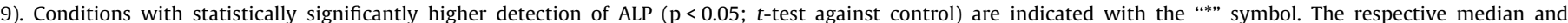

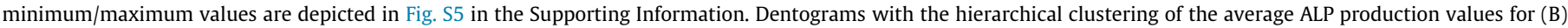
1 day and (C) 5 days of cell culture for static and dynamic conditions. 
yet. Although it has not induced an increase in ALP quantification alone, its mixture with ECM adhesive proteins, as fibronectin and collagen, has led to consistent increasing ALP detection. After 5 days of cell culture under static conditions ALP quantification levels were, in general, lower than at day 1, as compared to the protein-free control. The major positive effects on ALP quantification were observed in the conditions FV and FVA. For this timepoint, fibronectin clearly has a pronounced effect, as it appears several times on the conditions leading ALP increased expression. Tang et al. [65], verified that human plasma fibronectin coated on scaffold surfaces enhanced odontoblast-like cells proliferation, differentiation and mineralization. Conditions containing both vitronectin and amelogenin also led increased ALP quantification. Despite type I collagen has previously shown adjuvant effects on osteogenic differentiation of MSCs [44], and was mostly effective on promoting ALP production at day 1 , this effect was not observed at this time point. Different ECM cell-binding proteins have been proved to act through different pathways. For example, adult mesenchymal stem cells grown in 2D substrates treated with adsorbed vitronectin and type I collagen [44] are driven to osteogenesis through different mechanisms. Whereas vitronectin correlated with enhanced focal adhesion formation, the activation of focal adhesion kinase (FAK) and paxillin, and the diminished activation of extracellular signal-regulated kinase (ERK) and phosphatidylinositol-3 kinase (PI3K) pathways, on type-I collagen the osteogenic differentiation occurred with lower focal adhesion formation, reduced activation of FAK and paxillin, and increased activation of ERK and PI3K. The simultaneous stimulation of different pathways in combinatorial biomaterial formulations, along with 3D culture conditions (in opposition to conventionally used two-dimensional platforms), may hide the cues to explain the complex results observed in the studied array.

After one day under flow, the formulations A, VC, FEA, ECA and FECA led the highest detection of ALP. Here, the effect of amelogenin alone and in combination with other conditions is visible and was detected with statistic significant on a multivariate effect assessment of the mean average values of ALP ratios $(p<0.03)$. Conditions that promoted the highest osteogenic pathway response indicate a possibly positive effect of type-I collagen in coordination with amelogenin under dynamic flow conditions, in opposition to the observations on static culture setup. The relevance of amelogenin in this process is evidenced by, for example, analyzing cell response on EC composition, which rendered one of the lowest ALP quantification ratios, in opposition to the high ALP-inducing ECA. The adjuvant and predominant effect of amelogenin and some of its combinations is also visible after 5 days of cell culture in the bioreactor. The highest ALP quantification with low variation was observed for F, V, FV, EA, FVA and FEA formulations. In a similar way to the observations on static conditions, fibronectin in combination with other proteins shows a
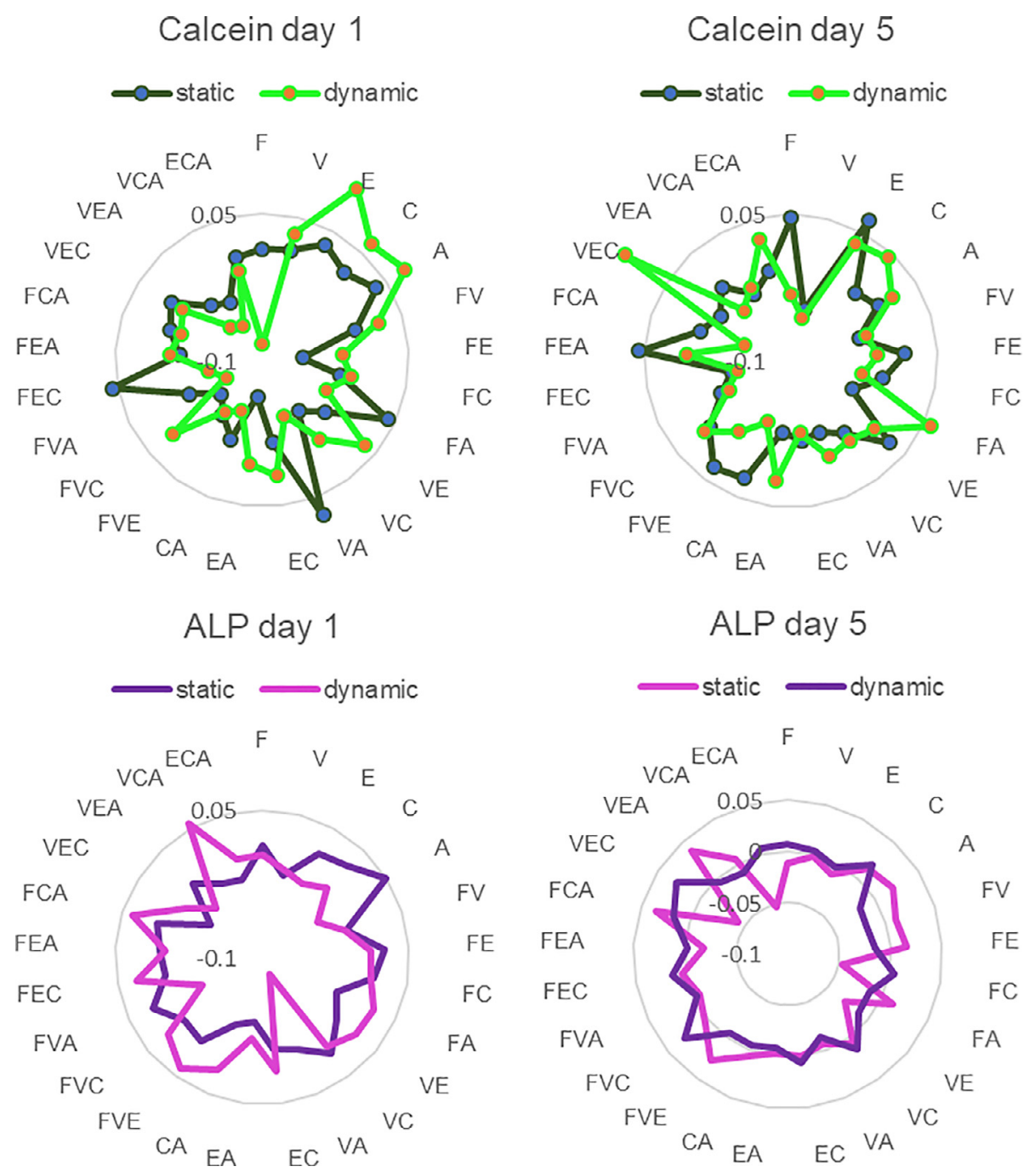

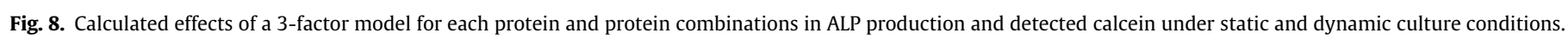


relevant role after 5 days of cell culture, in opposition to day 1 , in which its presence does not lead to an increase in ALP quantification.

In summary, after one day of cell culture higher ALP quantification seems to be dictated, both on static and dynamic conditions, by formulations rich in E-cadherin in combination with ECM proteins as fibronectin and vitronectin. On dynamic conditions, the presence of amelogenin in combination with ECM proteins seems to drive ALP production by BMSCs. At day 5 , the role of fibronectin is more preponderant, which is probably associated with the ability of this protein to induce cell adhesion and proliferation when covalently immobilized in chitosan substrates [66]. After 5 days of dynamic stimulation, the presence of amelogenin seems to promote an enhanced pre-osteogenic commitment, indicating a possible synergic relationship between the protein and the applied flow.

Surface response analysis is a useful tool to understand the role of different components on cellular outputs. A three-factor surface response analysis model enabled the identification of the effect of individual, binary and ternary combinations of proteins on the overall BMSCs response to biomaterials. Interesting trends including the simultaneous induction of cell attachment and ALP production by several proteins could be identified. For example, for static conditions, at day 1 , amelogenin was the main factor driving this trend (Fig. 8), while under dynamic conditions the presence of VE, EC and FVC dictated both higher cell number and early ALP production.

\section{Discussion}

The technology reported here allowed the affordable and rapid assessment of protein-BMSCs interactions under static and dynamic flow perfusion conditions. The system is adaptable to the application of different flow rates and administration timings (e.g. discrete or continuous), controlled through a programable peristaltic pump. The device allowed the application of uniform flow on all individual miniaturized porous scaffolds.

Each individual component of the bioreactor - i.e., the developed hollowed platform used to incorporate biomaterials and the bioreactor chamber - shows versatility and may be adapted to numerous configurations. Patterned biomaterials may be processed with distinct shapes and sizes by modulating the hollows of the arrayed platform. Additionally, the system may be directed for the future studies with different cell culture media, variable flows, multiple cell types (and even co-culture setups), as well as biomaterials combinations. The versatility and easy modulation of the bioreactor properties make it an appealing tool to be used for breakthrough discoveries on healthcare fields, including regenerative medicine, drug discovery and disease model/organ-on-achip development.

The flat configuration and precise array position of the 3D scaffolds in the developed hollow platforms make them compatible with the use of automatized robots, commonly used in the preparation of high-throughput devices. Several perfused chambers containing PDMS perforated arrayed platforms can be assembled in parallel or in series on commercially available multichannel perfusion pumps. For example, in Fig. $2 \mathrm{C}$ two parallel chambers are assembled in one single peristaltic pump. The parallelizable nature of this bioreactor allows to: (i) increase time effectiveness of the experiments, because several independent platforms can be studied in simultaneous, (ii) study increased numbers of replicates, as several platforms prepared under the same experimental conditions can be simultaneously assessed using stem cells from controlled batches, and (iii) potentiate the effective high-throughput versatility of this system, because a virtually unlimited number of conditions can be simultaneously studied. The diameter and volume capacity of the syringes used to assemble the bioreactor chamber may be modulated, enabling the exposure of a different number of scaffolds to flow perfusion conditions. This versatility may also be useful to increase the number of studied conditions per independent experiments, allowing the retrieval of large amounts of experimental data. On the contrary, the use of miniaturized biomaterials may be useful to limit the volume of cell culture medium necessary to perform each experiment, especially in the case of cell culture media supplemented with costly recombinant molecules (e.g. growth factors).

A literature survey focused on the dynamic stimulation of mesenchymal stem cells seeded onto 3D biomaterials with shear stress values in the range of the ones attained in this study mostly correlate dynamic culture conditions with increased cell proliferation and, inconsistently, both unaltered and increased ALP production [52]. The exposure of MSCs to low mechanical stimulatory signals have been correlated with a lower MSCs differentiation into the adipogenic lineage, and enhanced differentiation into osteoblasts [67]. The improvement of MSCs osteogenic differentiation by shear flow, and in particular ALP upregulation, has been correlated with p38 and ERK activation [68], and also with COX-2 upregulation, which may regulate the bone morphogenic protein (BMP) pathway $[69,70]$. However, the comparison between different studies must be performed carefully, since several factors rarely coincide between different literature reports; those include (i) the chemical and structural nature of the studied biomaterials, (ii) the uniformity of shear stress distribution in the scaffolds, and (iii) the frequency of the application of the flow. This variation leads to major difficulties in the establishment of reliable comparisons between bioreactor systems and their respective biological outputs. Concerning the role of homogenous distribution of shear stress onto biomaterials, Egger et al. [54] presented a study where similar shear stress values were posed to cells, while flow distribution inside 3D scaffolds served as a main modulator of osteogenesis. The average shear stress values calculated for each bioreactor configuration were in the same order of magnitude: 8 and 9.6 mPa. However, flow distribution inside the trabecular scaffolds' structures differed between the two setups concerning homogeneity, and a more inhomogeneous distribution of the flow on scaffolds' walls was correlated with higher ALP activity and matrix mineralization [54]. The application of our system enables the simultaneous flow stimulation of arrays of biomaterials under the same shear stress conditions, allowing a direct comparison between studied formulations.

The biomaterial array screened in this study enabled hitspotting different proteins as promoters of cell adhesion and ALP production in BMSCs. The role of protein combinations was also studied, although analysis must be performed carefully and restricted to the presence/absence of proteins, without quantitybased assumptions. The combined effect of cell-matrix and cellcell interactions has been recently explored as a potent modulator of stem cells lineage commitment [41,71]. Previous studies have focused on the exposure of 3D encapsulated mesenchymal stem cells to ECM adhesive proteins and soluble growth factors [72]. The characterization of the interplay between stem cells with integrin-mediated cell-matrix (including full proteins), cell-cell contact proteins, and other biologically relevant aspects (including mechanical stimulation [73]) is, however, still poorly described. Here, two main components - amelogenin and E-cadherin - were found as enhancers, but no sole players, in the achievement of biomaterial compositions capable of simultaneously increase cell adhesion and ALP secretion. E-cadherin regulates calciumdependent cell-cell adhesion [74], and is present in cells from the epithelial lineage, such as epithelial stem cells (ESCs) [75]. Nonetheless, for biomaterial-modification purposes E-cadherin has been suggested as a component of biomaterials capable of 
inducing MSCs proliferation and inhibiting apoptosis [76]. E-cadherin is involved in cell adhesion, proliferation, migration and differentiation [77], and its function is reported to go beyond the establishment of cell-cell junctions; for example, it is known that it takes part in signaling pathways, including the Rho GTPase signaling $[78,79]$. The recurrent presence of amelogenin in hitspotted formulations may indicate a correlation between this cell adhesion protein [80] and mechanotransduction phenomenon observed in the dynamic conditions assays. Indeed, amelogenin has been reported as capable of inducing osteogenic differentiation of embryonic stem cells through the activation of the Wnt pathway [81].

The interplay between protein composition and dynamic stimulation was shown to modulate cell adhesion and ALP production in a different manner than in static cell culture. Despite enabling the retrieval of high amounts of data, the strategy presented here was applied in a setup common to most high-throughput strategies: biomaterials were tested under shared cell culture medium - which may lead to crosstalk phenomena -, and data was assessed only by image analysis. The identified effects and hit-spotted biomaterials may be used in future approaches as a starting point to design and validate biomaterials with minimal cues to drive osteogenesis. We envision the further use of the developed system on long-term studies targeting osteogenesis and other tissue regeneration setups. The versatility of the method potentiates future tests using wider arrays of surface-modifying molecules, along with other cell types, driving new discoveries in the fields of biomaterials development for tissue regeneration, drug discovery and disease models design.

\section{Conclusion}

An arrayed hollow platform was developed to incorporate independent 3D miniaturized porous biomaterials that were modified with 31 different protein formulations present in bone ECM, cellcell contact junctions and enamel. The interactions between each individual biomaterial combination and human BMSCs were tested on static cell culture conditions, as well as under a dynamic perfusion flow. The results obtained in this study, with 64 conditions assessed per time point, allowed concluding about the importance of multiprotein formulations on the triggering of cell adhesion and osteogenic commitment of BMSCs. Hit-spotted formulations leading to high cell adhesion and ALP quantification consisted of mixtures of ECM-adhesive proteins (namely, fibronectin, type-I collagen and vitronectin) with cell-cell contact proteins (E-cadherin) and, with a high consistency, amelogenin. Cell response and hit-spotted biomaterial formulations were highly dependent on the application of flow perfusion on the whole system. This proof-of-concept work allowed proving the potential of the developed high-throughput system to test cell-biomaterials interactions under flow.

\section{Acknowledgements}

M.B. Oliveira acknowledges the financial support from Portuguese Foundation for Science and Technology- FCT (Grant SFRH/BPD/111354/2015). This work was developed within the scope of the projects CICECO-Aveiro Institute of Materials, POCI-01-0145-FEDER-007679 (FCT Ref. UID /CTM /50011/2013) and IPC/i3N Minho (FCT Ref. UID/ CTM/50025/2013), financed by national funds through the FCT/MEC and when appropriate co-financed by FEDER under the PT2020 Partnership Agreement. This work was also supported by European Research Council grant agreement ERC2014-ADG-669858 (project ATLAS).

\section{Appendix A. Supplementary data}

Supplementary data to this article can be found online at https://doi.org/10.1016/j.actbio.2019.06.047.

\section{References}

[1] S.A. Eming, P. Martin, M. Tomic-Canic, S. Traub, D. Ben-David, G.A. Kuhn, R. Müller, E. Livne, S.A. Eming, J.A. Hubbell, Wound repair and regeneration: mechanisms, signaling, and translation, Sci. Transl. Med. 6 (2014) 265sr6, https://doi.org/10.1126/scitranslmed.3009337.

[2] J.F. Mano, Designing biomaterials for tissue engineering based on the deconstruction of the native cellular environment, Mater. Lett. (2014), https://doi.org/10.1016/j.matlet.2014.11.061.

[3] R.H. Harrison, J.-P. St-Pierre, M.M. Stevens, Tissue engineering and regenerative medicine: a year in review, Tissue Eng. B. Rev. 20 (2014) 1-16, https://doi.org/10.1089/ten.TEB.2013.0668.

[4] M. Xue, C.J. Jackson, Extracellular matrix reorganization during wound healing and its impact on abnormal scarring. Adv. Wound Care 4 (2015) 119-136, https://doi.org/10.1089/wound.2013.0485.

[5] C. Frantz, K.M. Stewart, V.M. Weaver, The extracellular matrix at a glance, J Cell Sci. 123 (2010) 4195-4200, https://doi.org/10.1242/jcs.023820.

[6] D. Lopes, C. Martins-Cruz, M.B. Oliveira, J.F. Mano, Bone physiology as inspiration for tissue regenerative therapies, Biomaterials 185 (2018) 240275, https://doi.org/10.1016/J.BIOMATERIALS.2018.09.028.

[7] S. Bosi, R. Rauti, J. Laishram, A. Turco, D. Lonardoni, T. Nieus, M. Prato, D. Scaini, L. Ballerini, From 2D to 3D: novel nanostructured scaffolds to investigate signalling in reconstructed neuronal networks, Sci. Rep. 5 (2015) 9562, https:// doi.org/10.1038/srep09562.

[8] N. Gupta, J.R. Liu, B. Patel, D.E. Solomon, B. Vaidya, V. Gupta, Microfluidicsbased 3D cell culture models: Utility in novel drug discovery and delivery research, Bioeng. Transl. Med. 1 (2016) 63-81, https://doi.org/10.1002/ btm2.10013.

[9] S. Hinderer, S.L. Layland, K. Schenke-Layland, ECM and ECM-like materials biomaterials for applications in regenerative medicine and cancer therapy, Adv. Drug Deliv. Rev. 97 (2016) 260-269, https://doi.org/10.1016/j. addr.2015.11.019.

[10] Y. Zhang, M. Chopp, Z.G. Zhang, M. Katakowski, H. Xin, C. Qu, M. Ali, A. Mahmood, Y. Xiong, Systemic administration of cell-free exosomes generated by human bone marrow derived mesenchymal stem cells cultured under 2D and $3 \mathrm{D}$ conditions improves functional recovery in rats after traumatic brain injury, Neurochem. Int. 111 (2017) 69-81, https://doi.org/10.1016/j. neuint 2016.08.003.

[11] H.-W. Kang, S.J. Lee, I.K. Ko, C. Kengla, J.J. Yoo, A. Atala, A 3D bioprinting system to produce human-scale tissue constructs with structural integrity, Nat. Biotechnol. 34 (2016) 312-319, https://doi.org/10.1038/nbt.3413.

[12] K. Kamei, Y. Koyama, Y. Tokunaga, Y. Mashimo, M. Yoshioka, C. Fockenberg, R. Mosbergen, O. Korn, C. Wells, Y. Chen, Characterization of phenotypic and transcriptional differences in human pluripotent stem cells under 2D and 3D culture conditions, Adv. Healthc. Mater. 5 (2016) 2951-2958, https://doi.org/ 10.1002/adhm.201600893.

[13] S. González, H. Mei, M.N. Nakatsu, E.R. Baclagon, S.X. Deng, A 3D culture system enhances the ability of human bone marrow stromal cells to support the growth of limbal stem/progenitor cells, Stem Cell Res. 16 (2016) 358-364 https://doi.org/10.1016/j.scr.2016.02.018

[14] E. Ozcivici, Y.K. Luu, B. Adler, Y.-X. Qin, J. Rubin, S. Judex, C.T. Rubin, Mechanical signals as anabolic agents in bone, Nat. Rev. Rheumatol. 6 (2010) 50-59, https://doi.org/10.1038/nrrheum.2009.239.

[15] X. Wang, J.S. Nyman, X. Dong, H. Leng, M. Reyes, Fundamental biomechanics in bone tissue engineering, Synth. Lect. Tissue Eng. 2 (2010) 1-225, https://doi. org/10.2200/S00246ED1V01Y200912TIS004.

[16] J.R. Vetsch, R. Müller, S. Hofmann, The evolution of simulation techniques for dynamic bone tissue engineering in bioreactors, J. Tissue Eng. Regen. Med. 9 (2015) 903-917, https://doi.org/10.1002/term.1733.

[17] M. Ding, S.S. Henriksen, D. Wendt, S. Overgaard, An automated perfusion bioreactor for the streamlined production of engineered osteogenic grafts, J. Biomed. Mater. Res. B Appl. Biomater. 104 (2016) 532-537, https://doi.org/ 10.1002/jbm.b.33407.

[18] B. Carpentier, P. Layrolle, C. Legallais, Bioreactors for bone tissue engineering, Int. J. Artif. Organs 34 (2011) 259-270, https://doi.org/10.5301/ IJAO.2011.6333.

[19] G.M. de Peppo, I. Marcos-Campos, D.J. Kahler, D. Alsalman, L. Shang, G. VunjakNovakovic, D. Marolt, Engineering bone tissue substitutes from human induced pluripotent stem cells, Proc. Natl. Acad. Sci. 110 (2013) 8680-8685, https://doi.org/10.1073/pnas.1301190110.

[20] A.L. Zydney, Continuous downstream processing for high value biological products: a review, Biotechnol. Bioeng. 113 (2016) 465-475, https://doi.org/ $10.1002 /$ bit.25695.

[21] A.B. Yeatts, J.P. Fisher, Bone tissue engineering bioreactors: dynamic culture and the influence of shear stress, Bone 48 (2011) 171-181, https://doi.org/ 10.1016/j.bone.2010.09.138.

[22] G.N. Bancroft, V.I. Sikavitsas, A.G. Mikos, Technical Note: design of a flow perfusion bioreactor system for bone tissue-engineering applications, Tissue Eng. 9 (2003) 549-554, https://doi.org/10.1089/107632703322066723. 
[23] V.I. Sikavitsas, J.S. Temenoff, A.G. Mikos, Biomaterials and bone mechanotransduction, Biomaterials 22 (2001) 2581-2593.

[24] G.N. Bancroft, V.I. Sikavitsas, J. van den Dolder, T.L. Sheffield, C.G. Ambrose, J.A. Jansen, A.G. Mikos, Fluid flow increases mineralized matrix deposition in 3D perfusion culture of marrow stromal osteoblasts in a dose-dependent manner, Proc. Natl. Acad. Sci. 99 (2002) 12600-12605, https://doi.org/10.1073/ pnas.202296599.

[25] V.I. Sikavitsas, G.N. Bancroft, H.L. Holtorf, J.A. Jansen, A.G. Mikos, Mineralized matrix deposition by marrow stromal osteoblasts in 3D perfusion culture increases with increasing fluid shear forces, Proc. Natl. Acad. Sci. USA 100 (2003) 14683-14688, https://doi.org/10.1073/pnas.2434367100.

[26] N. Datta, Q.P. Pham, U. Sharma, V.I. Sikavitsas, J.A. Jansen, A.G. Mikos, In vitro generated extracellular matrix and fluid shear stress synergistically enhance 3D osteoblastic differentiation, Proc. Natl. Acad. Sci. 103 (2006) 2488-2493, https://doi.org/10.1073/pnas.0505661103.

[27] V. Abraham, D.L. Taylor, J.R. Haskins, High content screening applied to largescale cell biology, Trends Biotechnol. 22 (2004) 15-22, https://doi.org/ 10.1016/j.tibtech.2003.10.012.

[28] F. Guillemot, A. Souquet, S. Catros, B. Guillotin, J. Lopez, M. Faucon, B. Pippenger, R. Bareille, M. Rémy, S. Bellance, P. Chabassier, J.C. Fricain, J Amédée, High-throughput laser printing of cells and biomaterials for tissue engineering, Acta Biomater. 6 (2010) 2494-2500, https://doi.org/10.1016/j. actbio.2009.09.029.

[29] V.Z. Beachley, M.T. Wolf, K. Sadtler, S.S. Manda, H. Jacobs, M.R. Blatchley, J.S Bader, A. Pandey, D. Pardoll, J.H. Elisseeff, Tissue matrix arrays for highthroughput screening and systems analysis of cell function, Nat. Methods 12 (2015) 1197-1204, https://doi.org/10.1038/nmeth.3619.

[30] K.-H. Nam, A.S.T. Smith, S. Lone, S. Kwon, D.-H. Kim, Biomimetic 3D tissue models for advanced high-throughput drug screening, J. Lab. Autom. 20 (2015) 201-215, https://doi.org/10.1177/2211068214557813.

[31] M.B. Oliveira, J.F. Mano, High-throughput screening for integrative biomaterials design: exploring advances and new trends, Trends Biotechnol. 32 (2014) 627-636, https://doi.org/10.1016/j.tibtech.2014.09.009.

[32] H.-O. Ho, C.-C. Hsiao, C.-Y. Chen, T.D. Sokoloski, M.-T. Sheu, Fibrin-based drug delivery systems. II. The preparation and characterization of microbeads, Drug Dev. Ind. Pharm. 20 (1994) 535-546, https://doi.org/10.3109/ 03639049409038316.

[33] S.C. Desbordes, D.G. Placantonakis, A. Ciro, N.D. Socci, G. Lee, H. Djaballah, L. Studer, High-throughput screening assay for the identification of compounds regulating self-renewal and differentiation in human embryonic stem cells, Cell Stem Cell. 2 (2008) 602-612, https://doi.org/10.1016/j.stem.2008.05.010.

[34] Q. Zhou, P.T. Kühn, T. Huisman, E. Nieboer, C. van Zwol, T.G. van Kooten, P. van Rijn, Directional nanotopographic gradients: a high-throughput screening platform for cell contact guidance, Sci. Rep. 5 (2015) 16240, https://doi.org/ $10.1038 /$ srep 16240

[35] C.G. Simon, S. Lin-Gibson, Combinatorial and high-throughput screening of biomaterials, Adv. Mater. 23 (2011) 369-387, https://doi.org/10.1002/ adma.201001763.

[36] Á.J. Leite, M.B. Oliveira, S.G. Caridade, J.F. Mano, Screening of nanocomposite scaffolds arrays using superhydrophobic-wettable micropatterns, Adv. Funct. Mater. 27 (2017) 1701219, https://doi.org/10.1002/adfm.201701219.

[37] A. Dolatshahi-Pirouz, M. Nikkhah, A.K. Gaharwar, B. Hashmi, E. Guermani, H Aliabadi, G. Camci-Unal, T. Ferrante, M. Foss, D.E. Ingber, A. Khademhosseini, A combinatorial cell-laden gel microarray for inducing osteogenic differentiation of human mesenchymal stem cells, Sci. Rep. 4 (2015) 3896, https://doi.org/ 10.1038/srep03896.

[38] M.B. Oliveira, C.L. Salgado, W. Song, J.F. Mano, Combinatorial on-chip study of miniaturized 3D porous scaffolds using a patterned superhydrophobic platform, Small 9 (2013) 768-778, https://doi.org/10.1002/smll.201201436.

[39] M.B. Oliveira, M.P. Ribeiro, S.P. Miguel, A.I. Neto, P. Coutinho, I.J. Correia, J.F Mano, In vivo high-content evaluation of three-dimensional scaffolds biocompatibility, Tissue Eng. C. Methods 20 (2014) 851-864, https://doi.org 10.1089/ten.TEC.2013.0738.

[40] A.J. García, Get a grip: Integrins in cell-biomaterial interactions, Biomaterials 26 (2005) 7525-7529, https://doi.org/10.1016/j.biomaterials.2005.05.029.

[41] S.L. Vega, M.Y. Kwon, K.H. Song, C. Wang, R.L. Mauck, L. Han, J.A. Burdick, Combinatorial hydrogels with biochemical gradients for screening 3D cellular microenvironments, Nat. Commun. 9 (2018) 614, https://doi.org/10.1038/ s41467-018-03021-5.

[42] M. Sun, G. Chi, J. Xu, Y. Tan, J. Xu, S. Lv, Z. Xu, Y. Xia, L. Li, Y. Li, Extracellular matrix stiffness controls osteogenic differentiation of mesenchymal stem cells mediated by integrin $\alpha 5$, Stem Cell Res. Ther. 9 (2018), https://doi.org/ 10.1186/s13287-018-0798-0.

[43] S.K. Min, H.K. Kang, S.Y. Jung, D.H. Jang, B.M. Min, A vitronectin-derived peptide reverses ovariectomy-induced bone loss via regulation of osteoblas and osteoclast differentiation, Cell Death Differ. 25 (2018) 268-281, https:// doi.org/10.1038/cdd.2017.153.

[44] R.M. Salasznyk, W.A. Williams, A. Boskey, A. Batorsky, G.E. Plopper, Adhesion to vitronectin and collagen I promotes osteogenic differentiation of human mesenchymal stem cells, J. Biomed. Biotechnol. 2004 (2004) 24-34, https:// doi.org/10.1155/S1110724304306017.

[45] K. Tanimoto, Y.C. Huang, Y. Tanne, R. Kunimatsu, M. Michida, M. Yoshioka, N Ozaki, T. Sasamoto, Y. Yoshimi, Y. Kato, K. Tanne, Amelogenin enhances the osteogenic differentiation of mesenchymal stem cells derived from bone marrow, Cells Tissues Organs 196 (2012) 411-419, https://doi.org/10.1159/ 000335912.

[46] Y. Zhang, H. Mao, C. Gao, S. Li, Q. Shuai, J. Xu, K. Xu, L. Cao, R. Lang, Z. Gu, T. Akaike, J. Yang, Enhanced biological functions of human mesenchymal stemcell aggregates incorporating e-cadherin-modified PLGA microparticles, Adv. Healthc. Mater. 5 (2016) 1949-1959, https://doi.org/10.1002/ adhm.201600114.

[47] C.A. Custódio, C.M. Alves, R.L. Reis, J.F. Mano, Immobilization of fibronectin in chitosan substrates improves cell adhesion and proliferation, J. Tissue Eng. Regen. Med. 4 (2010) 316-323, https://doi.org/10.1002/term.248.

[48] N.E. Reticker-Flynn, D.F.B. Malta, M.M. Winslow, J.M. Lamar, M.J. Xu, G.H. Underhill, R.O. Hynes, T.E. Jacks, S.N. Bhatia, A combinatorial extracellular matrix platform identifies cell-extracellular matrix interactions that correlate with metastasis, Nat. Commun. 3 (2012) 1122, https://doi.org/10.1038/ ncomms 2128.

[49] A. Haze, A.L. Taylor, S. Haegewald, Y. Leiser, B. Shay, E. Rosenfeld, Y. Gruenbaum-Cohen, L. Dafni, B. Zimmermann, K. Heikinheimo, C.W. Gibson, L.W. Fisher, M.F. Young, A. Blumenfeld, J.P. Bernimoulin, D. Deutsch, Regeneration of bone and periodontal ligament induced by recombinant amelogenin after periodontitis, J. Cell. Mol. Med. 13 (2009) 1110-1124, https://doi.org/10.1111/j.1582-4934.2009.00700.x.

[50] K. Yang, J. Lee, S.-W. Cho, Engineering biomaterials for feeder-free maintenance of human pluripotent stem cells, Int. J. Stem Cells 5 (2012) 1-5.

[51] H. Jasak, OpenFOAM: open source CFD in research and industry, Int. J. Nav. Archit. Ocean Eng. 1 (2009) 89-94, https://doi.org/10.2478/IJNAOE-20130011.

[52] R.J. McCoy, F.J. O'Brien, Influence of shear stress in perfusion bioreactor cultures for the development of three-dimensional bone tissue constructs: a review, Tissue Eng. B Rev. 16 (2010) 587-601, https://doi.org/10.1089/ten. teb.2010.0370.

[53] B. Porter, R. Zauel, H. Stockman, R. Guldberg, D. Fyhrie, 3-D computational modeling of media flow through scaffolds in a perfusion bioreactor, J. Biomech. 38 (2005) 543-549, https://doi.org/10.1016/j.jbiomech.2004.04.011.

[54] D. Egger, M. Fischer, A. Clementi, V. Ribitsch, J. Hansmann, C. Kasper, Development and characterization of a parallelizable perfusion bioreactor for 3D cell culture, Bioengineering 4 (2017) 51, https://doi.org/10.3390/ bioengineering 4020051.

[55] H.-J. Prins, A.K. Braat, D. Gawlitta, W.J.A. Dhert, D.A. Egan, E. Tijssen-Slump, H. Yuan, P.J. Coffer, H. Rozemuller, A.C. Martens, In vitro induction of alkaline phosphatase levels predicts in vivo bone forming capacity of human bone marrow stromal cells, Stem Cell Res. 12 (2014) 428-440, https://doi.org/ 10.1016/j.scr.2013.12.001.

[56] R.V. Prigodich, M.R. Vesely, Characterization of the complex between bovine osteocalcin and type I collagen, Arch. Biochem. Biophys. 345 (1997) 339-341.

[57] B.J. Dzamba, H. Wu, R. Jaenisch, D.M. Peters, Fibronectin binding site in type I collagen regulates fibronectin fibril formation, J. Cell Biol. 121 (1993) 11651172.

[58] A.S. Charonis, E.C. Tsilibary, P.D. Yurchenco, H. Furthmayr, Binding of laminin to type IV collagen: a morphological study, J. Cell Biol. 100 (1985) 1848-1853, https://doi.org/10.1083/JCB.100.6.1848.

[59] S. Heydarkhan-Hagvall, J.M. Gluck, C. Delman, M. Jung, N. Ehsani, S. Full, R.J. Shemin, The effect of vitronectin on the differentiation of embryonic stem cells in a 3D culture system, Biomaterials 33 (2012) 2032-2040, https://doi.org/ 10.1016/j.biomaterials.2011.11.065.

[60] C.J. Flaim, S. Chien, S.N. Bhatia, An extracellular matrix microarray for probing cellular differentiation, Nat. Methods 2 (2005) 119-125, https://doi.org/ $10.1038 /$ nmeth736.

[61] J. Kirkham, I. Andreev, C. Robinson, S.J. Brookes, R.C. Shore, D.A. Smith, Evidence for direct amelogenin-target cell interactions using dynamic force spectroscopy, Eur. J. Oral Sci. 114 (2006) 219-224, https://doi.org/10.1111/ j.1600-0722.2006.00290.x.

[62] S.B. Lokappa, K.B. Chandrababu, J. Moradian-Oldak, Tooth enamel protein amelogenin binds to ameloblast cell membrane-mimicking vesicles via its $\mathrm{N}$ terminus, Biochem. Biophys. Res. Commun. 464 (2015) 956-961, https://doi. org/10.1016/j.bbrc.2015.07.082

[63] S.B. Lokappa, K.B. Chandrababu, K. Dutta, I. Perovic, J.S. Evans, J. MoradianOldak, Interactions of amelogenin with phospholipids, Biopolymers 103 (2015) 96-108, https://doi.org/10.1002/bip.22573.

[64] A. Di Benedetto, M. Watkins, S. Grimston, V. Salazar, C. Donsante, G. Mbalaviele, G.L. Radice, R. Civitelli, N-cadherin and cadherin 11 modulate postnatal bone growth and osteoblast differentiation by distinct mechanisms, J. Cell Sci. 123 (2010) 2640-2648, https://doi.org/10.1242/jcs.067777.

[65] J. Tang, T. Saito, Human plasma fibronectin promotes proliferation and differentiation of odontoblast, J. Appl. Oral Sci. 25 (2017) 299-309, https:// doi.org/10.1590/1678-7757-2016-0442.

[66] A.K. Kundu, A.J. Putnam, Vitronectin and collagen I differentially regulate osteogenesis in mesenchymal stem cells, Biochem. Biophys. Res. Commun. 347 (2006) 347-357, https://doi.org/10.1016/j.bbrc.2006.06.110.

[67] C.T. Rubin, E. Capilla, Y.K. Luu, B. Busa, H. Crawford, D.J. Nolan, V. Mittal, C.J. Rosen, J.E. Pessin, S. Judex, Adipogenesis is inhibited by brief, daily exposure to high-frequency, extremely low-magnitude mechanical signals, Proc. Natl. Acad. Sci. 104 (2007) 17879-17884, https://doi.org/10.1073/ pnas.0708467104. 
236

D. Lopes et al./Acta Biomaterialia 96 (2019) 222-236

[68] M. Grellier, R. Bareille, C. Bourget, J. Amédée, Responsiveness of human bone marrow stromal cells to shear stress, J. Tissue Eng. Regen. Med. 3 (2009) $302-$ 309, https://doi.org/10.1002/term.166.

[69] T. Arikawa, K. Omura, I. Morita, Regulation of bone morphogenetic protein-2 expression by endogenous prostaglandin E2 in human mesenchymal stem cells, J. Cell. Physiol. 200 (2004) 400-406, https://doi.org/10.1002/jcp.20031.

[70] A.B. Yeatts, D.T. Choquette, J.P. Fisher, Bioreactors to influence stem cell fate: augmentation of mesenchymal stem cell signaling pathways via dynamic culture systems, Biochim. Biophys. Acta 2013 (1830) 2470-2480, https://doi. org/10.1016/j.bbagen.2012.06.007.

[71] B.D. Cosgrove, K.L. Mui, T.P. Driscoll, S.R. Caliari, K.D. Mehta, R.K. Assoian, J.A. Burdick, R.L. Mauck, N-cadherin adhesive interactions modulate matrix mechanosensing and fate commitment of mesenchymal stem cells, Nat Mater. 15 (2016) 1297-1306, https://doi.org/10.1038/nmat4725.

[72] L. Hou, J. Coller, V. Natu, T.J. Hastie, N.F. Huang, Combinatorial extracellular matrix microenvironments promote survival and phenotype of human induced pluripotent stem cell-derived endothelial cells in hypoxia, Acta Biomater. 44 (2016) 188-199, https://doi.org/10.1016/j.actbio.2016.08.003.

[73] M. Nii, J.H. Lai, M. Keeney, L.-H. Han, A. Behn, G. Imanbayev, F. Yang, The effects of interactive mechanical and biochemical niche signaling on osteogenic differentiation of adipose-derived stem cells using combinatorial hydrogels, Acta Biomater. 9(2013)5475-5483, https://doi.org/10.1016/j.actbio.2012.11.002.

[74] B.M. Gumbiner, Regulation of cadherin-mediated adhesion in morphogenesis, Nat. Rev. Mol. Cell Biol. 6 (2005) 622-634, https://doi.org/10.1038/nrm1699.
[75] A.M. Eastham, H. Spencer, F. Soncin, S. Ritson, C.L.R. Merry, P.L. Stern, C.M. Ward, Epithelial-mesenchymal transition events during human embryonic stem cell differentiation, Cancer Res. 67 (2007) 11254-11262, https://doi.org/ 10.1158/0008-5472.CAN-07-2253.

[76] Y. Zhang, H. Mao, M. Qian, F. Hu, L. Cao, K. Xu, Q. Shuai, C. Gao, R. Lang, T. Akaike, J. Yang, Surface modification with E-cadherin fusion protein for mesenchymal stem cell culture, J. Mater. Chem. B. 4 (2016) 4267-4277, https://doi.org/10.1039/C6TB00765A.

[77] L. Li, S.A.L. Bennett, L. Wang, Role of E-cadherin and other cell adhesion molecules in survival and differentiation of human pluripotent stem cells, Cell Adh. Migr. 6 (2012) 59-73, https://doi.org/10.4161/cam.19583.

[78] T. Pieters, F. van Roy, Role of cell-cell adhesion complexes in embryonic stem cell biology, J. Cell Sci. 127 (2014) 2603-2613, https://doi.org/10.1242/ jcs. 146720.

[79] U. Cavallaro, G. Christofori, Cell adhesion and signalling by cadherins and IgCAMs in cancer, Nat. Rev. Cancer 4 (2004) 118-132, https://doi.org/10.1038/ nrc1276.

[80] A.M. Hoang, R.J. Klebe, B. Steffensen, O.H. Ryu, J.P. Simmer, D.L. Cochran, Amelogenin is a cell adhesion protein, J. Dent. Res. 81 (2002) 497-500.

[81] R. Warotayanont, B. Frenkel, M.L. Snead, Y. Zhou, Leucine-rich amelogenin peptide induces osteogenesis by activation of the Wnt pathway, Biochem. Biophys. Res. Commun. 387 (2009) 558-563, https://doi.org/10.1016/j. bbrc.2009.07.058. 